\title{
Immunological Markers Detected in Peri-Implant Crevicular Fluid Detected by MSD Electromagnetic ELISA Assay - A Pilot Study of Dental Implant Patients
}

\author{
Paul Canallatos
}

Follow this and additional works at: https://researchrepository.wvu.edu/etd

\section{Recommended Citation}

Canallatos, Paul, "Immunological Markers Detected in Peri-Implant Crevicular Fluid Detected by MSD Electromagnetic ELISA Assay - A Pilot Study of Dental Implant Patients" (2017). Graduate Theses, Dissertations, and Problem Reports. 5308.

https://researchrepository.wvu.edu/etd/5308

This Thesis is protected by copyright and/or related rights. It has been brought to you by the The Research Repository @ WVU with permission from the rights-holder(s). You are free to use this Thesis in any way that is permitted by the copyright and related rights legislation that applies to your use. For other uses you must obtain permission from the rights-holder(s) directly, unless additional rights are indicated by a Creative Commons license in the record and/ or on the work itself. This Thesis has been accepted for inclusion in WVU Graduate Theses, Dissertations, and Problem Reports collection by an authorized administrator of The Research Repository @ WVU. For more information, please contact researchrepository@mail.wvu.edu. 
Immunological Markers Detected in Peri-Implant Crevicular Fluid Detected by MSD Electromagnetic ELISA Assay - A Pilot Study of Dental Implant Patients

Paul Canallatos, D.D.S.

Thesis submitted to the

\author{
School of Dentistry \\ At West Virginia University \\ in partial fulfillment of the requirements \\ for the degree of \\ Master of Science \\ In \\ Prosthodontics
}
Matthew S. Bryington, D.M.D., M.S. (Chair)
Bryan D. Dye, D.D.S., M.S.
Elizabeth Kao, D.M.D.

Department of Restorative Dentistry

Morgantown, West Virginia

2017

Keywords: Cytokines, Proinflammatory Markers, Peri-Implant Crevicular Fluid, Gingival Crevicular Fluid, Single-tooth Implant Restorations, Edentulous Implant Restoration, GCF, PICF, Interleukins, Immunology, Peri-Implantitis

Copyright 2017 Paul Canallatos 


\begin{abstract}
Immunological Markers Detected in Peri-Implant Crevicular Fluid Detected by MSD Electromagnetic ELISA Assay - A Pilot Study of Dental Implant Patients

Paul Canallatos, D.D.S
\end{abstract}

Objectives: The purpose of this pilot study is to determine if, in healthy states, there are significant differences in cytokine activity in peri-implant crevicular fluid (PICF) between implants restored in an edentulous patient (ES) and implants restored in a dentate patient (DS).

Methods: In this pilot study, peri-implant crevicular fluid was obtained from sixteen total patients -eight dentate patients restored with fixed restoration implants and eight edentulous patients restored with implant retained overdenture. Paper points were used to obtained the periimplant GCF and then were processed using the MSD Meso Quickplex SQ 120 machine. A 96well Proinflammatory Panel 1 (human) Kit V-Plex, coated with capture-antibodies to IFN- $\gamma$, IL$1 \beta$, IL-2, IL-4, IL-6, IL-8, IL-10, IL-12p70, IL-13, and, TNF- $\alpha$, and a 96-well Cytokine Panel 1 (Human) kit V-Plex, coated with capture-antibodies to GM-CSF, IL-1 $\alpha$, IL-5, IL-7, IL-12/23 p40, IL-15, IL-16, IL-17A, TNF- $\beta$, and, VEGF, were used and prepared exactly according to manufacturer specifications without deviation.

Results: There were significant differences between PICF of ES group and DS groups. Significant differences, at the $p<0.05$ interval, were noted in IL-1 $\alpha$, IL-12/23p40, IL-10, IL-15, and VEGF.

Conclusions: Statistically significant differences were detected between certain cytokines in PICF of dentate subjects compared to edentulous subjects. There was no correlation noted in the numerical concentrations of cytokines between the statistically significant differences. There is a tendency towards higher levels of cytokines/inflammatory markers in PICF of implants in dentate patients compared to edentulous patients 


\section{DEDICATION}

I would like to dedicate this paper to my wife, Jessica E. Canallatos. She has not only been a model person that I aspire to become, but she provides endless love and support by consistently believing in my strides towards success. 


\section{ACKNOWLEGEMENTS}

I would like to thank the following individuals for providing much needed guidance during my postdoctoral training:

Dr. Matthew S. Bryington, Thank you for providing a foundation for which my career can be built on. Your lessons and support over the last three years have provided the necessary confidence to be able to contribute to the dental community.

Dr. Bryan D. Dye, Thank you for your efficiency and support throughout this process. Your mentorship has made dreams become a reality. You have used your resources to better the education of those under your umbrella.

Dr. Rick Jurevic, Thank you for your support and guidance through this process, especially with guidance to use the laboratory and assistance with the MSD equipment, as well as organizing and filling out paperwork.

Dr. Elizabeth Kao, Thank you for your support and availability when your assistance was needed greatly.

Mr. Christopher Waters, Thank you for your guidance in the laboratory during the processing of the results. Your leadership in the laboratory has helped clarify difficult concepts to the untrained mind.

Dr. Gerald Hobbs, Thank you for your statistical expertise. 


\section{Table of Contents}

CHAPTER I: INTRODUCTION

BACKGROUND

Statement of THE Problem

3

SignificANCE OF THE PROBLEM

HYPOTHESIS

NULL HYPOTHESIS

DEFINITION OF TERMS

ASSUMPTIONS

LIMITATIONS

DELIMITATIONS

CHAPTER II: LITERATURE REVIEW

PERI-IMPlant MUCOSITIS/PERI-IMPlantitis

CYTOKINES

CYTOKINES IN ORAL ENVIRONMENT

Gingival Crevicular Fluid

Peri-Implant CREVicular Fluid

CHAPTER III: MATERIALS AND METHODS 22

PARTICIPANT ACQUISITION $\quad 22$

SAMPLE ACQUISITION $\quad 23$

PRocessing SAMPLES $\quad 24$

STATISTICAL ANALYSIS $\quad 25$

CHAPTER IV 26

$\begin{array}{lr}\text { RESULTS } & 26\end{array}$

\begin{tabular}{lr} 
CHAPTER V & 38 \\
\hline
\end{tabular}

$\begin{array}{ll}\text { DISCUSSION } & 38\end{array}$

\begin{tabular}{lr} 
CHAPTER VI: & 44 \\
\hline
\end{tabular}

$\begin{array}{ll}\text { SUMMARY } & 44\end{array}$

CONCLUSIONS $\quad 44$

\begin{tabular}{lr} 
REFERENCES & 45 \\
\hline
\end{tabular}

CURRICULUM VITAE $\quad 55$ 


\section{LIST OF TABLES}

Table 1: Calculated Concentration Means of Proinflammatory Markers for Edentulous Subjects (ES) $(\mathrm{pg} / \mathrm{ml})$

Table 2: Calculated Concentration Means of Proinflammatory Markers for Dentate Subjects (DS) $(\mathrm{pg} / \mathrm{ml})$

Table 3: ANOVA of Calculated Concentration Means of Proinflammatory Markers

Table 4: Calculated Concentration Means of Cytokine Markers for Edentulous Subjects (ES) $(\mathrm{pg} / \mathrm{ml})$

Table 5: Calculated Concentration Means of Cytokine Markers for Dentate Subjects (DS) $(\mathrm{pg} / \mathrm{ml})$

Table 6: ANOVA of Calculated Concentration Means of Cytokine Markers 


\section{LIST OF FIGURES}

Figure 1a. IL-10 Calculated Concentration Mean Plot

Figure 1b. Statistical Plot for Calculated Concentration Mean of IL-10

Figure 2a. IL-12/23p40 Calculated Concentration Mean Plot

Figure 2b. Statistical Plot for Calculated Concentration Mean of IL-12/23p40

Figure 3a. IL-15 Calculated Concentration Mean Plot

Figure 3b. Statistical Plot for Calculated Concentration Mean of IL-15

Figure 4a. IL-1 $\alpha$ Calculated Concentration Mean Plot

Figure 4b. Statistical Plot for Calculated Concentration Mean of IL-1 $\alpha$

Figure 5a. VEGF Calculated Concentration Mean Plot

Figure 5b. Statistical Plot for Calculated Concentration Mean of VEGF 


\section{LIST OF ABBREVIATIONS}

ANOVA - Analysis of Variance

ES - Edentulous Subject

DS - Dentate Subject

GCF - Gingival Crevicular Fluid

GM-CSF - Granulocyte, Macrophage Colony Stimulating Factor

IFN - Interferon

IL - Interleukin

NK - Natural Killer

PICF - Peri-Implant Crevicular Fluid

$\mathbf{P g} / \mathbf{m l}$ - Picograms per milliliter

PMN - Polymorphonuclear Leukocytes

Th1 - Help T Cells 1

Th2 - Helper T Cells 2 


\section{CHAPTER I: INTRODUCTION}

\section{Background}

Modern endosteal dental implants have been used to restore missing teeth effectively in North America since the 1980's. They have provided patients with a higher quality of life whether they are being used to retain removable dental prostheses or for fixed dental prostheses ${ }^{1}$. Their benefit to the field of prosthetic dentistry for the treatment of missing teeth has allowed for new treatment modalities to be explored. When planned from a restoratively- driven aspect, utilizing an appropriate surgical protocol, and proper restoration with adequate occlusion, implant success rates have been shown to be remarkably high, allowing the clinician to suggest dental implants as an excellent option when treatment planning with patients ${ }^{1}$.

As successful as implants have been, they have not been immune to complications and failures. Implant failures have been noted in the literature and the practices of those clinicians that choose to deal with implant therapy for patients ${ }^{1}$. Risk factors, whether local or systemic, have been reported to give clinicians an educated gauge as to the success a patient will have, prior to placement ${ }^{1}$. Implant failure has been shown to be multifactorial, at times, leaving the clinician unable to identify the cause of the progression from healthy to hopeless dental implants ${ }^{1}$. It would be highly beneficial if there were measurable indicators to help determine the health of an implant and whether or not it may be on its way to a diseased state.

Much like natural dentition, implants have a sulcus holding a fluid that contains multiple bacterial organisms and pro-inflammatory proteins. This peri-implant crevicular fluid, much like that of gingival crevicular fluid surrounding natural dentition, has a 
multitude of different elements within it that reflect the status of periodontal health that supports the implant ${ }^{1}$. This peri-implant crevicular fluid holds measurable indicators that could help clinicians determine whether or not an implant is healthy or displaying a shift in microflora/inflammatory markers that could be weakening the dental implant ${ }^{1}$. Inflammatory markers have not been studied to the extent of microbiota, thus looking farther into this aspect of oral health could bring us one step closer to understanding the etiology between peri-mucositis and peri-implantitis. Prior to understanding a diseased state, it is imperative to fully comprehend a healthy, stable environment. Nonetheless, a healthy environment for an implant restored in a dentate patient may be different than that of an implant placed in an edentulous patient. If these factors are measureable in the peri-implant crevicular fluid, one must question whether or not there are differences between implants in edentulous patients and implants in dentate patients. 


\section{Statement of the Problem}

1. In clinically healthy implants in healthy individuals, are there significant differences between the cytokines in the peri-implant crevicular fluid of implants in a dentate patient versus an edentulous patient restored with implants?

\section{Significance of the Problem}

Implants have become the standard of care for partially or fully edentulous patients $^{2}$. One of the problems with implants, despite being the standard of care, is that patients may have lost their dentition due to prior inadequate home care ${ }^{2,3}$. Peri-implant inflammation and failures is a problem clinicians face. Although bacterial plaque is considered the primary etiological factor of peri-implant diseases ${ }^{4-6}$, other factors play a significant role in these diseases, such as the intensity of the inflammatory response to bacterial products, like lipopolysaccharides and endotoxin ${ }^{4}$. These products generate cytokines' release by host inflammatory cells, thus leading to bone loss around implants ${ }^{4}$. Cytokines have been shown to have higher expression in diseased states ${ }^{4,7,8}$. This higher expression of proinflammatory cytokines can affect the $\mathrm{T}$ helper cell response, generating different patterns of cytokines expression ${ }^{7}$. Leading to an immune cell response, predominantly mediated by cytotoxic T cells, macrophages, neutrophils, and natural killer cells ${ }^{4}$, which ultimately leads to destruction of local tissues.

Researchers have found that even in conditions of minimal bacterial accumulation or clinical health, inflammatory cytokines may still be produced in substantial amounts ${ }^{9-}$

11. These biomarkers are indicators of a biological state and can help to distinguish between normal and pathological processes ${ }^{12}$. Currently, probing depths, clinical attachment level, radiographs, and bleeding on probing are used for diagnosis ${ }^{12,13}$. 
Biomarkers have advantages because of their non-invasive nature of being collected ${ }^{13}$. There is a wide range of percentages and causes of peri-implantitis. Researchers and clinicians are always looking for additional measures to aid in proper diagnosis and early detection of disease state by the measurement of levels of enzymes and biomarkers ${ }^{12}$. Currently, there are no definitive concentrations of cytokines that would deem a site to be diseased or healthy. Correlations have been established as to which markers are more prevalent in certain clinical situations ${ }^{14}$. Before a definitive concentration for diagnostic purposes could be obtained, it is important to have a baseline measurement of the clinical situation without evidence of disease. Two clinical situations that have not been compared to date are the constituents of peri-implant crevicular fluid around implants in dentate versus edentulous patients.

The purpose of this study is to determine if, in healthy states, significant differences are found in cytokine activity in peri-implant crevicular fluid between implants restored in an edentulous patient and implants restored in a dentate patient.

\section{Hypothesis}

There will be significant differences in proinflammatory markers and cytokine markers that are found in the peri-implant crevicular fluid of healthy implants when comparing implants in edentulous patients and implants in dentate patients.

\section{Null Hypothesis}

There will not be significant differences in proinflammatory markers and cytokine markers that are found in the peri-implant crevicular fluid of healthy implants when comparing implants in edentulous patients and implants in dentate patients. 


\section{Definition of Terms}

Cytokine: A large group of proteins made by cells that are capable of regulating a wide variety of cellular functions ${ }^{15}$.

Dentate: having teeth ${ }^{16}$.

Edentulous: without teeth, lacking teeth ${ }^{16}$.

ELISA: Acronym for enzyme-linked immunoadsorbent assay wherein an enzyme-antibody complex binds to an agent thought to be present in a sample.

Typically, an enzyme-activated dye is used to detect the presence of bound immunoglobulin-enzyme complex. The amount of color is proportional to the concentration of bound antibody/suspect agent present in the test sample ${ }^{15}$.

Gingival Crevicular Fluid (GCF): Tissue fluid that seeps through the crevicular and junctional epithelium. It is increased in the presence of inflammation ${ }^{15}$.

Inflammation: A localized protective response elicited by proximate microbes and/or tissue injury, which serves to destroy, dilute, or wall off both the injurious agent and the injured tissue. A cellular and vascular reaction of tissues to injury ${ }^{15}$.

Interleukin: A family of potent proteins that serves as a link between inducer and effector cells during immune and inflammatory responses; involved in the recruitment of immune and inflammatory precursor cells. Some interleukins have been implicated in the pathogenesis of periodontal disease ${ }^{15}$.

Microbiota: The microscopic living organisms of a region ${ }^{15}$.

Peri-Implantitis: a term used to describe inflammation around a dental implant, which is an irreversible condition that involves the breakdown of soft tissue and supporting bone. ${ }^{16}$. 
Periodontitis: Inflammation of the supporting tissues of the teeth. Usually a progressively destructive change leading to loss of bone and periodontal ligament. An extension of inflammation from gingiva into the adjacent bone and ligament ${ }^{15}$. Peri-Implant Crevicular Fluid (PICF): fluid surrounding an implant (see GCF) 


\section{Assumptions}

1. It is assumed the subjects understand the consent and the procedure that was performed.

2. It is assumed that all paper points and laboratory equipment were sterile.

3. It is assumed that there was no salivary contamination.

4. It is assumed the instrument used in this study is valid and reliable.

5. It is assumed the patients reported their medical history accurately and there were no systemic conditions present.

\section{Limitations}

1. The subjects of the study were limited to patients at West Virginia University School of Dentistry. Findings may not be representative of the larger, general population.

2. There was a limited sample size.

\section{Delimitations}

1. Subjects were chosen from the West Virginia University Graduate Prosthodontic clinic patient pool due to patients' familiarity with the clinic.

2. The amount of patients was determined by the limitations of the MSD Mesoscale plates that were available for researcher usage. 


\section{Chapter II: LITERATURE REVIEW}

\section{Peri-implant mucositis/Peri-implantitis}

Peri-implant diseases are important to understand in order to prevent failures of dental implants. Peri-implant diseases can present as either peri-implant mucositis or peri-implantitis. Both of these diseases are characterized by an inflammatory reaction in the tissues surrounding an implant ${ }^{14,17,18}$. Peri-implant mucositis has been described as inflammation of the surrounding implant tissue with no involvement of osseous structure or clinical attachment loss ${ }^{14}$. Peri-implantitis has been characterized by an inflammatory process around an implant, which includes both soft tissue inflammation and progressive loss of supporting bone beyond biological bone remodeling ${ }^{14,19}$. This disease can be caused by an imbalance between the bacterial load and host defense ${ }^{20}$, which could affect the mucosa, the bone, or both. In a review by Rosen et al in 2013, it was shown that peri-implant mucositis could occur in subjects $31 \%$ to $59.6 \%$ of the time between a time frame of 6.3 to 10.8 years, while peri-implantitis could occur in $16 \%$ to as much as, $47.1 \%$ of subjects between a time frame of 5.7 to 14 years after implant placement ${ }^{14}$. These numbers indicate that there is variability in the prevalence of these conditions, nonetheless, indicate that there is a problem that necessitates attention.

Detection of the disease will greatly influence the severity of its effects. The clinical signs of peri-implant mucositis include bleeding on probing and possibly suppuration $^{14}$, while peri-implantitis includes all of the clinical signs of peri-implant mucositis, in addition to bone loss. These clinical signs, if caught early enough, can aid in treatment that can reverse or prevent further damage. Peri-implant mucositis, much 
like gingivitis, is reversible when effectively treated ${ }^{14,21,22}$. Peri-implantitis, like periodontitis, occurs primarily as a result of a bacterial load and subsequent host immune response, leading to tissue breakdown ${ }^{14}$. There are inflammatory markers up- regulated by the immune system in peri-implantitis and periodontitis, which include, but are not limited to, IL-1, IL-6, IL-8, IL-12 and TNF $\alpha^{23,24}$. These markers signal local tissue destruction and will be discussed in sections below in further detail.

In an effort to foresee any complications, risk factors should be taken into consideration prior to commencement of implant therapy. Risk factors that have been well documented include history of periodontitis, diabetes, genetic traits, poor oral hygiene, smoking, alcohol consumption, absence of keratinized mucosa and implant surface, residual cement, occlusal overload ${ }^{14,20}$. History of periodontitis is significant when considering risk factors because it shows the effect adjacent teeth and their conditions could have on adjacent implants and their peri-implant tissue health. It has been shown that implant bone loss has been different in patients with a history of periodontitis and those who have not had this disease ${ }^{25-27}$. This indicates a strong influence of surrounding dentition on the implants' overall health. Karoussis et $a l^{26}$ performed a study which concluded that patients with a history of chronic periodontitis may have greater long-term marginal bone loss and incidence of peri-implantitis compared with periodontally healthy subjects. Diagnosing peri-implant mucositis before bone loss has occurred to be crucial to the prognosis of the implant before it can progress to peri-implantitis. 


\section{Cytokines}

Cytokines is the general term for a large group of molecules involved in signaling between cells during immune responses ${ }^{28}$. All cytokines are proteins or glycoproteins acting as molecular messengers that communicate information between cells. They induce their effects by binding to high-affinity receptors on target cell membranes and help recruit cells and vascularity to a local site ${ }^{29}$. They are categorized as interleukins, growth factors, chemokines, and interferons ${ }^{10}$. Interferons (IFNs) are important in limiting viral infections; for example, cells that have become infected by a virus produce IFN $\alpha$ and IFN $\beta$. IFN $\gamma$ is another type, which is released by activated T Helper 1 (Th1) cells and has been shown to be very active in periodontitis and local dental inflammation $^{28}$. Interleukins are produced mainly by $\mathrm{T}$ cells, though some are produced by mononuclear phagocytes, and cause other cells to divide and differentiate. Chemokines are a large group of chemotactic cytokines that direct the movement of leukocytes around the body. Finally, growth factors are very important in directing the division and differentiation of bone marrow stem cells and precursors of blood leukocytes into the necessary cell to handle the threat ${ }^{30}$. Among these, there is a small subset of cytokines that are important in mediating inflammation and cytotoxic reactions, these include the tumor necrosis factors, TNF $\alpha$ and $\mathrm{TNF} \beta^{28}$.

$\mathrm{T}$ cells are vital to the function of the immune system and are divided into $\mathrm{T}$ Helper 1 (Th1) and T Helper 2 (Th2) cells. Th1 cells release cytokines that promote interactions with mononuclear phagocytes, Th2 cells release a different set of cytokines to activate $\mathrm{B}$ cells ${ }^{28}$. These cytokines aid in the interaction between these cells, instructing them to either recruit more cells or to perform an action. Each cytokine does 
not solely have one function, but are part of an integrated web that allows the human immune system to function ${ }^{30}$.

Cytokines that were chosen in this study are regularly mediators of inflammation and infection. The cytokine plates that were used contain several antibodies raised against a specific protein applied to the tray. Each cytokine that was tested in this study will be introduced in the following paragraphs. Interleukin -1 (IL-1) is divided into two forms: IL- $\alpha$ and IL- $\beta$. Interleukin- $1 \beta$ eta is the predominant form of IL- 1 , which is primarily produced by macrophages. Interleukin -1 alpha have very similar structure to that of IL-1 $\beta$, but are encoded by separate genes ${ }^{31}$. Just like IL-1 $\beta$, they act on endothelial cells to increase attachment of neutrophils and monocytes, thus recruiting these cells to the site of inflammation. IL- $\alpha$ is produced primarily by macrophages. The cellular origin of IL- $1 \alpha$ is speculative, according to Masada et $a l^{31}$, and ten times less likely to be found than IL-1 $\beta$.

Interleukin-4 (IL-4) is produced by plasma cells, and they promote TH2 and activate B-cells and antibody production. Antibodies that are produced by IL-4 can be protective by helping elimination of infection ${ }^{32}$, Interleukin 6 is a multifunctional protein that stimulates immunoglobulin secretion by human B-lympthocytes and activates Tcells $^{33}$, It has also been shown to play a major role in terminal differentiation of Blymphocytes to plasma cells, which are predominantly inflammatory ${ }^{33}$. Interleukin-8 (IL8 ) is a classical inflammatory cytokine that is produced by macrophages and epithelial cells, which stimulates neutrophil chemotaxis during bacterial exposure ${ }^{11,34,35}$. Interleukin-10 (IL-10) is produced by TH2 cells and inhibits cytokine production of TH1 
cells, which has an inhibitory effect on macrophage-monocytes, thus giving it an antiinflammatory effect ${ }^{36,37}$.

Although present in the literature, IL-2, IL-5, IL-7, IL-12, IL-13, IL-15, IL-16, and IL-17 are not widely discussed from a dental aspect, but they play a powerful role in inflammation. Interleukin -2 (IL-2) is produced by activated T cells and they are involved in T cell proliferation and differentiation, B Cell proliferation, and cytolytic activity $^{28}$. Interleukin-5 (IL-5) is made by T lymphocytes, and cause B lymphocytes to increase in proliferation and eosinophils to be activated and proliferate. Interleukin (IL7), produced by the stromal cells, is a major factor in supporting pre-B cell growth, alongside IL- ${ }^{28,30}$. Interleukin-12 (IL-12) has multiple variations that are named after the receptors that they bind to. IL-12p30 and IL-12/23 p40 are made by monocytes and B cells. These both induce IFN $-\gamma$ production by T and Natural Killer (NK) cells and inhibit Ig E production. Interleukin-13 (IL-13) is produced by activated T and B cells. IL-13 causes B cell growth and differentiation factor and stimulates chemotaxis. Interleukin-15 (IL-15) is produced by mononuclear cells and NK cells. They stimulate activated B, T and NK cells and chemoattractant. Interleukin-16 (IL-16) is produced by $\mathrm{T}$ cells and eosinophil and has chemotaxis capabilities for CD4 cells. Interleukin-17 (IL17) is produced by Th17 cells and is a regulator of inflammation in various aspects ${ }^{28}$.

Tumor necrosis factor (TNF) is present in two forms: TNF-alpha (TNF- $\alpha$ ) and TNF-beta(TNF- $\beta$ ). TNF- $\alpha$ is made by macrophages and lymphocytes. It can activate macrophages, granulocytes and cytotoxic cells, stimulate angiogensis, and induce cell adhesion. TNF- $\beta$ are made by mast cells, platelets, and fibroblasts and are important in wound repair, cell growth regulation, tissue remodeling and immunosuppression ${ }^{30}$. 
Vacular endothelial growth factor (VEGF) plays a role in diseased and healthy sites, suggesting that its presence maintains periodontal health, but it is also present in chronic inflammatory periodontal disease ${ }^{38}$. VEGF induces other functional alterations in endothelial cells $^{38,39}$, causing vascular permeability, and is crucial in neovascularization ${ }^{38}$. Due to its role in angiogenesis, it is a prominent feature of both inflammation and healing. VEGF has been shown to be induced by IL-1 and TNF- $\alpha .^{38}$

Interferon gamma (IFN- $\gamma$ ) is made by T cells and NK cells. It can increase phagocytosis of PMNs and macrophages by activating them, inhibiting progression of infection. They also induce endothelial cell/lymphocyte adhesion ${ }^{40}$. Granulocyte macrophage colony stimulating factor (GM-CSF) comes from T cells, macrophages, endothelial cell, and B cells, and they inhibit apoptosis, proliferation, differentation and activation of granulocytes and macrophages ${ }^{28}$.

These cytokines are displayed throughout the body, in varying quantities depending on the threat or pathogen that is presently disrupting the normal homeostasis. Our focus will be drawn to the cytokines that have had the most influence in the oral cavity.

\section{Cytokines in Oral Environment}

There is a continuous balance that exists between host immune response and potential subgingival pathogens around teeth. This continuous balance shines light on the fact that there will always be inflammatory markers that are present around teeth, even if they are clinically healthy ${ }^{9,41}$. These inflammatory markers, or cytokines, act as signals and feedback to the body to either activate an immune response or keep the status quo. Cytokines have a dose-response curve that shows that although these markers might be 
present, they don't always elicit a negative response unless the quantity surpasses a threshold ${ }^{41}$. Once the threshold is met, it activates the immune system.. To date, no numerical concentration of cytokines has been determined to which a.response will be clinically seen.

Innate response cytokines are necessary for the recruitment of polymorphonuclear leukocytes (PMNs), specifically by IL-8, and subsequent stimulation of monocytes, macrophages, and PMNs (IL-1 $\beta$ and TNF- $\alpha$ ). Vascular changes are also related to these cytokines (IL-1 $\beta$ and TNF- $\alpha$ ), allowing for the transmigration of inflammatory cells within the connective tissues and through the sulcus ${ }^{10,42}$. Low levels of PMNs in clinically healthy gingival tissues are common findings around healthy teeth (and implants), thus low levels of IL- 8 should be observed since it is produced by PMNs ${ }^{43}$. It is critical to understand the different markers to appreciate what the clinical situation may be if they are elevated. There is a fine line between healthy and preinflammatory states. It has been shown that levels of IL-1 $\beta$ and IL- 8 in GCF can be elevated before clinical signs of inflammation appear ${ }^{44}$. Zhang et al ${ }^{45}$ proved this in their gingivitis model that showed that after three days of plaque accumulation, there were elevated levels of IL-1 $\beta$ before clinical signs of inflammation appeared ${ }^{45}$. Increased levels of IL-1 have been reported in periodontitis and gingivitis. IL-1 enables recruitment of cells towards infection sites, promotes bone resorption, and stimulates prostaglandin (PGE2) release by monocytes and fibroblasts, and release of metalloproteinases that degrade extracellular matrix proteins ${ }^{36,46,47}$. IL-1 $\beta$ is thoroughly studied in the literature, alongside with TNF- $\alpha$. IL-1 $\beta$ and TNF- $\alpha$ appear to play major roles in mediating the inflammatory response in the pathogenesis of many chronic inflammatory diseases ${ }^{9,48,49}$. 
Due to its role in chronic inflammatory disease, IL-1 $\beta$ is found at elevated levels in GCF in periodontitis and peri-implant inflammation. IL-1 $\beta$ is produced primarily by monocytes, or by other nucleated cells, in response to injury and has elevated levels when associated with periodontitis ${ }^{9,36,46,47}$. Nonetheless, IL- $1 \alpha$ and IL-1 $\beta$ are the principal inflammation induced cytokines stimulating bone resorption in periodontitis ${ }^{11,50,51}$.

Tsai $e t a l^{40}$ showed that IL-4 was much higher after scaling and root planing was performed, which supports the finding that it may play a role in regulating the degree of local inflammation in periodontal disease. IL-6 has a major role in terminal differentiation of B-lymphocytes to plasma cells giving it proinflammatory effects that are responsible for collagen resorption of gingival tissues ${ }^{9,41}$. It has been shown to be involved in established and advanced periodontal disease $\mathrm{s}^{33,52}$. Sakai et $\mathrm{l}^{11}$ found that IL8 is significantly higher in diseased states yet still present at significant levels in healthy states. IL-8 is considered to be a mediator of granulocyte accumulation ${ }^{36,53-55}$.

TNF- $\alpha$ is similar to IL-8 and is also found in sites affected by periodontitis. These two act synergistically to initiate the cascade of inflammatory mediators ${ }^{9}$. Other cytokines that are involved in this process, such as IL-12, appear to induce the secretion of Interferon (IFN- $\gamma$ ) from activated T and Natural Killer (NK) cells ${ }^{56}$, and IL-8 acts as a potent chemoattractant for neutrophils ${ }^{57}$.

Periodontal disease is a process by which there is cellular destruction of the supporting structures of the teeth. Major tissue destruction in established periodontitis lesions results from recruitment of host cells via activation of different cell types ${ }^{36}$. Proinflammatory cytokines are synthesized in response to periodontopathogenic bacteria 
and their byproducts, hence inducing an inflammatory response in the periodontium $^{36,58,59}$.

The oral environment has the ability to stimulate and depress the immune system, depending on the status of the threat it is trying to combat. IL-6 and IL-10 can inhibit the production of cytokines, lessening the effect of destruction ${ }^{36,60}$. IL-6 may act as an antiinflammatory by inhibiting the production of IL-1 $\beta$ and TNF- $\alpha$ in conjunction with IL-10. Phagocytosis, or the engulfment and destruction of cells or material ${ }^{61}$, is necessary to remove unwanted foreign substance or excess cells that were created to combat whatever threat was present. IL-12 is responsible for controlling phagocytosis ${ }^{10}$.

As evident in the literature, cytokines can give an adequate snapshot into the health of an implant or tooth in the oral cavity. Acquisition of these materials have been studied whether through saliva, blood, or the sulcular fluids. Blood is a possible medium through which cytokines can be tested, but it is more systemic and will not give the local picture that is directly adjacent to the object in question. Saliva also has many other factors that can offer a general idea of the oral cavity, but it cannot be used to study localized areas. Sulcular or crevicular fluid has been a widely studied sample due to its ease of acquisition and the components that are specific to the substance in which it surrounds, in addition to the fact that this fluid is closest to the structure in question.

\section{Gingival Crevicular Fluid}

It has been known that gingival crevicular fluid, or sulcular fluid, has defense mechanisms since the work of Waerhaug and Brill and Krasse in the $1950 \mathrm{~s}^{62}$. Studying sulcular fluid has been very popular in the periodontal world due to the non-invasive methods of acquisition and its snapshot into the health of the structure it surrounds. 
Dorland's medical dictionary ${ }^{61}$ defines the fluid as the interstitial fluid and plasma that seeps into the gingival sulcus. Brill and Krasse showed the similarities in composition between this fluid and the bloodstream ${ }^{63}$. Sulcular fluid, in small quantities, can hold substances that can build up or destroy the structure that it surrounds. Challacombe stated that gingival crevicular fluid could has a volume of 0.43 to $1.56 \mu$ l could be found in the interproximal spaces between molar teeth ${ }^{64}$. In this minute amount of fluid, there are cellular elements, electrolytes, organic compounds, and enzymes. Due to its components, this fluid has been studied to potentially develop patient-specific diagnostic tests for periodontal disease $e^{65}$.

\section{Peri-Implant Crevicular Fluid}

Peri-implant crevicular fluid (PCIF) is remarkably similar to gingival crevicular fluid $^{9}$. The same gradient exists between the blood stream and the sulcus that exists between the gingival tissue and the implant surface or abutment ${ }^{9}$. Due to its similarities with gingival crevicular fluid, focus should be drawn to the differences between these two substances. When analyzing the substituents in the PICF, cytokine production was at higher levels in contrast to natural dentition ${ }^{10}$. It has been suggested that implants act as a foreign object, which results in these higher cytokine secretions ${ }^{9}$. For many years, titanium has been considered as the most biologically compatible material for the fabrication of implants of different kinds, but Nowzari et al ${ }^{10}$ found higher concentrations of cytokines around implants, which raised questions for other authors to answer as to why these concentrations were higher ${ }^{10,66}$. Cadosch et $a l^{66}$ found that because implants are not entirely inert, a slow liberation of titanium molecules is possible, and in 
conjunction with bacterial accumulation, this would give the explanation as to why implants may have higher cytokine levels than natural dentition has. ${ }^{10,66}$ In addition to the titanium molecules, Perala and colleagues indicated that dental implant surfaces may lead to an activation of human mononuclear cells (Lymphocytes, NK cells, T Cells) for the secretion of IL- $1 \beta$ and TNF- $\alpha^{9,67}$. These two cytokines can lead to bone resorption and collagen degradation ${ }^{9}$.

Due to the foreign nature of their composition to the human body, dental implants are at a disadvantage, except susceptibility to caries, when compared to natural dentition. In addition to this setback, implants are also battling against similar bacterial accumulation as teeth are. Papaioannou et $a l^{68}$ have studied the similarities between periodontal pathogens that cause periodontitis and the periodontal pathogens that cause peri-implantitis. They reported that patients with high numbers of periodontal pathogens around teeth are at an increased risk of cross-infection with bacteria from periodontal sites to implants ${ }^{23,68}$. It has been widely studied that periodontitis and peri-implantitis are closely linked, thus showing a strong influence of the dental GCF composition on PICF 23,69-72.

Due to this close relationship, de Waal et $a l^{73}$ performed a review evaluating periimplant microflora between fully and partially edentulous patients. A review of a study by Socransky $e t a l^{74}$ revealed that the "hard tissue" surfaces influence the composition of the biofilm, and the gingival crevicular fluid is essential for the colonization of these bacteria $^{73}$. This was supported in a study that showed a significant reduction of periodontal pathogens (Aggregatibacter actinomycetemcomitans and Porphyromonas gingivalis) after full mouth extraction ${ }^{75}$, but had higher detection frequencies after 
implant placement and with an increasing detection rate the longer the implants were in function $^{76}$. In fully edentulous patients, the bacteria in biofilms originate primarily from intraoral soft tissues while partially edentulous patients have bacteria that originates from the subgingival area of neighboring teeth ${ }^{73}$. Great similarities in the composition of the subgingival microflora at implants and teeth within the same mouth have been found ${ }^{73,77-}$

79. It has been shown that partially edentulous patients harbor more potentially pathogenic peri-implant microflora compared to fully edentulous patients. ${ }^{73}$.

As stated earlier, cytokines have a direct correlation to the types of bacteria that are present. The components of the immune system, especially cytokines, that are designed to protect the body from pathogenic bacteria, can attack the periodontium. Evidence indicates that inflammatory cytokines, released by the host's monocytes and macrophages in response to bacterial products such as lipopolysaccharide (LPS) and endotoxin, are responsible for breakdown of periodontium in periodontitis ${ }^{2,80,81}$. Thus, studies have been aimed at determining which cytokines are collected in high levels during peri-implant inflammation. Teles et $a l^{44}$ reported that higher levels of interleukins (IL-1 $\beta$ and IL-8) in "clinically healthy" sites suggest that inflammatory mechanisms take place within the gingival tissues, in both GCF and PICF, before they can be clinically detected.

Another important cytokine that plays an important role in inflammatory response is vascular endothelial growth factor (VEGF). Higher levels of VEGF have been found around inflamed peri-implant tissues with deep peri-implant pockets compared with healthy implant tissues ${ }^{82}$. Thus, Nogueira-Filho et $a l^{82}$ concluded that low levels of VEGF may indicate clinical stability in peri-implant tissues. 
Peri-implant inflammation may be affected by local factors other than bacterial biofilms, such as implant system and location of the micro-gap ${ }^{10,82}$.

Concerning amounts of PICF, it was noted that PICF fluid volume is increased when probing depths have increased and in cases where inflammation is present ${ }^{65}$. Along with the amount of fluid, quantities of cytokines in PICF have attempted to be measured to make a standard for diagnosis. At the current time, PICF as a single measure cannot account for the complexity of the whole system; therefore, a number of objective measures and clinical judgment remain important to establish the early diagnosis of a failing implant ${ }^{83}$. This study is a pilot study used to determine if baseline measurements could be obtained for implants in dentate subjects and implants in edentulous subjects. It is hopeful that this study will warrant future studies aiming to investigate baseline measurements of different healthy clinical situations in order to obtain a range of numerical values that a diagnostician could use to compare to ailing implants. 


\section{Chapter III: MATERIALS AND METHODS}

\section{Participant Acquisition}

Participants were obtained from the patients of West Virginia University Graduate Prosthodontics clinic. Utilizing and Institutionally Reviewed Protocol (IRB\#1506713764), a thorough review of active and recall patients, within the department, was performed. A total of sixteen patients were recruited-eight dentate patients with implants (DS) and eight edentulous patients with implants (ES). A total of one implant per patient was sampled. Due to ease of isolation, if multiple implants were present, the most anterior implant's PICF was sampled due to ease of isolation. All patients included were in good systemic health with no signs of clinical peri-implantitis or peri-implant mucositis. Exclusion criteria for this study included anyone presenting with local periodontal or systemic disease. Local disease was characterized by bleeding on probing, clinical attachment loss, more than four millimeters of periodontal probing depth, and radiographic bone loss that was not stable in the last year. Systemic diseases excluded were poorly controlled diabetes, current smokers, metabolic bone disease, and

immunocompromised or autoimmune disorders. Patients were also excluded if they had any antibiotic or steroidal treatments within the last three months. All patients had implants in function for at least 6 months to no variability with adaptation to a new 
restoration. Once patients were obtained, they were assigned a subject number, 1-8 for edentulous patients with implants (ES) and 9-16 for dentate patients with implants (DS). A master list with the patient's name and assigned number was kept in the locked office of the principal investigators office within the Graduate Prosthodontics clinic. Anonymity was maintained throughout the entirety of the experiment and documentation of the experiment. Patients were properly informed of the clinical implications of the experiment, including risks and benefits of the procedures. Each patient was given a written consent, which was reviewed aloud, and then ample time was given to review the information before consenting to treatment. Once documentation was complete, the experiment commenced.

\section{Sample Acquisition}

Once patients were consented, PICF sampling commenced. Two different experiments were run at the same time in order to measure a wide variety of cytokine markers. The MSD Meso Quickplex SQ 120 machine electrochemical ELISA machine (MSD, Gaithersburg, MD) was used for processing of samples. Due to availability, two different plates were used to allow for maximum amount of cytokines to be tested. For each plate, ten inflammatory markers were tested. Following manufacturer's recommended protocols, cytokines were divided into two different plates according to cross-reactivity and dilution factors that allow them to be optimally placed together. The two plates were named by MSD as Proinflammatory Panel 1 (human) Kit V-Plex, which had antibodies to IFN- $\gamma$, IL-1 $\beta$, IL-2, IL-4, IL-6, IL-8, IL-10, IL-12p70, IL-13, and, TNF$\alpha$, and Cytokine Panel 1 (Human) kit V-Plex, which had antibodies to GM-CSF, IL-1 $\alpha$, IL-5, IL-7, IL-12/23 p40, IL-15, IL-16, IL-17A, TNF- $\beta$, and, VEGF. 
Properly labeled $1.8 \mathrm{ml}$ vials with $1.0 \mathrm{ml}$ of TE Buffer, provided by MSD Mesoscale, were used. Each patient had two sealed vials with TE Buffer labeled either P (Proinflammatory) or Cy (Cytokines) followed by their corresponding pre-assigned subject number. Using cotton roll isolation and $2 \times 2$ gauze, the site was dried of any extra-sulcular fluids. Six medium absorbent paper points, (BencoDental, Wilkes-Barre, PA) were used for each implant, collecting samples from mesiofacial, midfacial, distofacial, distolingual, midlingual, and mesiolingual. To ensure adequate sample, no more than two paper points were inserted into the peri-implant sulcus at a time. They remained in the sulcus for 30 seconds, and then they were placed into the labeled vial. In all 16 subjects, the six absorbent paper points that were used to run the proinflammatory markers plates were gathered first, followed by the acquisition of the samples for the cytokine markers. A minimum of 5 minutes passed between proinflammatory and cytokine sample gathering to ensure adequate replenishment of peri-implant crevicular fluid. Once all samples were gathered, they were immediately placed into a portable freezer and brought to the main laboratory to be stored in a labeled container and placed in a -20 degree Celsius freezer.

\section{Processing Samples}

The samples were processed on the MSD Meso Quickplex SQ 120 machine (MSD, Gaithersburg, MD). The samples were thawed and prepared using manufacturer's protocol, under sterile conditions and utilizing solutions provided by the MSD company (MSD, Gaithersburg, MD). These solutions include calibrator stock, control stock, detection antibody stock, wash buffer, and read buffer T. A 96-well Proinflammatory Panel 1 (human) Kit V-Plex, coated with capture-antibodies to IFN- $\gamma$, IL-1 $\beta$, IL-2, IL-4, 
IL-6, IL-8, IL-10, IL-12p70, IL-13, and, TNF- $\alpha$, and a 96-well Cytokine Panel 1

(Human) kit V-Plex, coated with capture-antibodies to GM-CSF, IL-1 $\alpha$, IL-5, IL-7, IL12/23 p40, IL-15, IL-16, IL-17A, TNF- $\beta$, and, VEGF, were used and prepared according to manufacturer specifications. Detection antibodies were coupled with SULFOTAG labels which emit a light when electrochemically stimulated via carbon-coated electrodes at the bottom of each well (MSD, Gaithersburg, MD). To ensure accuracy, all samples were duplicated on the plate, in different wells, to ensure accuracy. The mean of these concentrations were used for the raw data. Data was analyzed by MSD Mesoscale Discovery Workbench 4.0.

\section{Statistical Analysis}

Calculated concentration values, displayed in picograms per milliliters, were obtained from the sixteen samples. These calculated concentration values were obtained for each of the proinflammatory and cytokine markers. A mean concentration value was calculated for each sample. The mean value of the calculated concentration was calculated and obtained by MSD Mesoscale Discovery Workbench Software.

For each proinflammatory and cytokine marker, the calculated concentration mean was obtained for the two groups, compared using a One-Way ANOVA. JMP® Pro Version 12 (Cary, NC) was used to statistically evaluate data comparing the dentate and edentulous groups. Significant value between the groups was set at $\mathrm{p}<0.05$. 


\section{Chapter IV}

\section{RESULTS}

A total of sixteen patients were evaluated for this study. Eight subjects were in the completely-edentulous restored with implants group (ES) and eight subjects were in the dentate restored with single implant crown group (DS). Each subject had enough sample taken to ensure adequate amounts to be run on two different plates. Each sample was duplicated within the cytokine and proinflammatory plate to determine the accuracy of the processing of each sample. The mean values were calculated for each sample. For the purposes of this research study, calculated concentration mean was used to compare the differences between edentulous and dental implant groups.

\section{Proinflammatory Results}

A total of ten proinflammatory markers, including IFN- $\gamma$, IL-1 $\beta$, IL-2, IL-4, IL-6, IL-8, IL-10, IL-12p70, IL-13, and, TNF- $\alpha$, were tested in all sixteen subjects. Data for edentulous subjects is listed in Table 1 and data for dentate subjects is listed in Table 2. If the quantity of calculated concentration mean was too low to be detected, that sample was excluded from the measurements for that particular marker. The concentrations that were detected by MSD machine are in red font. These are considered to be in the detection range which is determined by the calibrators. The calibrators are determined by the National Institute for Biological Stands and Control, as well as World Health Organization. The cytokines that fail to register are weighted heavily on fewer results 
leading to a less reliable conclusion. The total amount of observations and the mean of the concentrations are listed in Table 3. The amount of detected concentrations for edentulous subjects is listed under ES and the amount of detected concentrations for dentate subjects is listed under DS. The F ratio and P values are listed, including statistically significant values highlighted in red $(\mathrm{p}<0.05)$. For all markers, there was an overall higher level ( $\mathrm{pg} / \mathrm{ml})$ of calculated concentration in DS than in ES subject groups, with exception to IL-4, which showed very similar values. The highest mean response was for IL-8 being $94.77 \mathrm{pg} / \mathrm{ml}$ and the lowest response for IL-4 at $0.11 \mathrm{pg} / \mathrm{ml}$. IL-10 was significantly different between the DS group and the ES group with a p value of 0.044 . There is a tendency that shows difference between concentrations found in ES and DS when concerning IL-13 and TNF- $\alpha$, but these were not statistically significant. The data for IL-10 in graph representation, shown in Figure 1, shows approximately half of the samples below detection range and half of the samples within the detection range. The detection range is predetermined by the software which includes the lower limit of detection, which is is a calculated concenttration 2.5 standard deviations above the lowest point on the calibration curve, and the upper limit of detection is the highest calibrator point. The curve is a standard curve, which the software generates by using raw signals from calibrators. The plots that are below the detection range show that there was not a significant concentration when compared to the calibrators. All 16 samples recorded a value for IL-10. 
Table 1: Calculated Concentration Means of Proinflammatory Markers for Edentulous Subjects (ES) $(\mathrm{pg} / \mathrm{ml})$

\begin{tabular}{|c|c|c|c|c|c|c|c|c|c|c|}
\hline- & IFN- $\gamma$ & IL-10 & IL-12p70 & IL-13 & IL-1 $\beta$ & IL-2 & IL-4 & IL-6 & IL-8 & TNF- $\alpha$ \\
\hline ES 01 & 0.228 & 0.019 & 0.040 & - & 3.644 & - & 0.014 & 0.190 & 0.269 & 0.269 \\
\hline ES 02 & - & 0.005 & 0.036 & 0.824 & 1.555 & - & 0.007 & 0.328 & 0.511 & 0.511 \\
\hline ES 03 & - & 0.124 & 0.020 & 0.531 & 4.673 & 0.029 & 0.014 & 1.171 & 1.691 & 1.691 \\
\hline ES 04 & 0.409 & 0.267 & 0.026 & 3.674 & 56.315 & 0.079 & - & 0.145 & 0.772 & 0.772 \\
\hline ES 05 & - & 0.044 & - & 0.727 & 5.700 & - & - & 0.173 & 0.335 & 0.335 \\
\hline ES 06 & 0.689 & 0.128 & 0.043 & 1.065 & 4.448 & - & 0.010 & 0.426 & 1.714 & 1.714 \\
\hline ES 07 & 0.093 & 0.119 & 0.045 & - & 12.173 & - & - & 0.123 & 0.143 & 0.143 \\
\hline ES 08 & 0.428 & 0.035 & 0.015 & - & 1.087 & 0.060 & - & 0.185 & 0.291 & 0.291 \\
\hline Average & 0.369 & 0.093 & 0.032 & 1.364 & 11.199 & 0.056 & 0.011 & 0.343 & 0.716 & 0.716 \\
\hline Max & 0.689 & 0.267 & 0.045 & 3.674 & 56.315 & 0.079 & 0.014 & 1.171 & 1.714 & 1.714 \\
\hline Min & 0.093 & 0.005 & 0.015 & 0.531 & 1.087 & 0.029 & 0.007 & 0.123 & 0.143 & 0.143 \\
\hline
\end{tabular}

* Data in red indicates that the concentration was in detection range

Table 2: Calculated Concentration Means of Proinflammatory Markers for Dentate Subjects (DS) $(\mathrm{pg} / \mathrm{ml})$

\begin{tabular}{|c|c|c|c|c|c|c|c|c|c|c|}
\hline- & IFN- $\boldsymbol{\gamma}$ & IL-10 & \multicolumn{1}{l|}{ IL-12p70 } & IL-13 & \multicolumn{1}{l}{ IL-1 } & \multicolumn{1}{|l|}{ IL-2 } & IL-4 & IL-6 & IL-8 & TNF- $\boldsymbol{\alpha}$ \\
\hline DS 09 & - & 0.121 & 0.021 & - & 12.668 & - & - & 0.578 & 1.298 & 1.298 \\
\hline DS 10 & 3.602 & 0.938 & 0.086 & 5.924 & 88.875 & 0.219 & 0.006 & 1.578 & 5.622 & 5.622 \\
\hline DS 11 & 0.882 & 1.675 & 0.037 & 2.576 & 81.604 & 0.128 & 0.012 & 0.503 & 0.963 & 0.963 \\
\hline DS 12 & 0.461 & 0.048 & 0.051 & - & 4.323 & - & 0.008 & 0.116 & 0.449 & 0.449 \\
\hline DS 13 & 0.976 & 0.346 & 0.012 & 2.437 & 21.000 & 0.121 & 0.017 & 0.937 & 4.086 & 4.086 \\
\hline DS 14 & 0.646 & 0.662 & 0.071 & 2.990 & 13.562 & 0.080 & 0.003 & 0.160 & 1.367 & 1.367 \\
\hline DS 15 & 4.007 & 2.584 & 0.060 & 2.724 & 35.179 & 0.134 & 0.020 & 1.529 & 2.376 & 2.376 \\
\hline DS 16 & 0.194 & 0.067 & 0.027 & - & 15.898 & 0.044 & - & - & 0.137 & 0.137 \\
\hline Average & 1.538 & 0.805 & 0.046 & 3.330 & 34.139 & 0.121 & 0.011 & 0.772 & 2.037 & 2.037 \\
\hline Max & 4.007 & 2.584 & 0.086 & 5.924 & 88.875 & 0.219 & 0.020 & 1.578 & 5.622 & 5.622 \\
\hline Min & 0.194 & 0.048 & 0.012 & 2.437 & 4.323 & 0.044 & 0.003 & 0.116 & 0.137 & 0.137 \\
\hline
\end{tabular}

* Data in red indicates that the concentration was in detection range 
Table 3: ANOVA of Calculated Concentration Means of Proinflammatory Markers

\begin{tabular}{|ccccccc|}
\hline MARKER & ES & DS & Total Observations & Mean of Response & F Ratio & P VALUES \\
\hline IFN- $\mu$ & 5 & 7 & 12 & 1.051332 & 2.6453 & 0.134913359 \\
\hline IL-10 & 8 & 8 & 16 & 0.448905 & 4.8939 & $0.044078421^{\text {a }}$ \\
\hline IL-12p70 & 7 & 8 & 15 & 0.039295 & 1.5555 & 0.234330213 \\
\hline IL-13 & 5 & 5 & 10 & 2.347231 & 5.0233 & 0.055316075 \\
\hline IL-1 $\beta$ & 8 & 8 & 16 & 22.66913 & 2.9658 & 0.107051177 \\
\hline IL-2 & 3 & 6 & 9 & 0.099298 & 3.1539 & 0.119004092 \\
\hline IL-4 & 4 & 6 & 10 & 0.011114 & 0.0004 & 0.984327461 \\
\hline IL-6 & 8 & 7 & 15 & 0.542834 & 2.9572 & 0.10919505 \\
\hline IL-8 & 8 & 8 & 16 & 94.76917 & 2.2078 & 0.159486735 \\
\hline TNF- $\alpha$ & 8 & 8 & 16 & 1.376372 & 3.4573 & 0.084116424 \\
\hline \multicolumn{7}{c}{ Represents significant differences at the P $<0.05$ interval (JMP/Pro } \\
Ver12, SAS Inst. Inc., Cary, NC). & & & \\
\end{tabular}


Figure 1a. IL-10 Calculated Concentration Mean Plot (MSD Discovery Workbench 4.0)

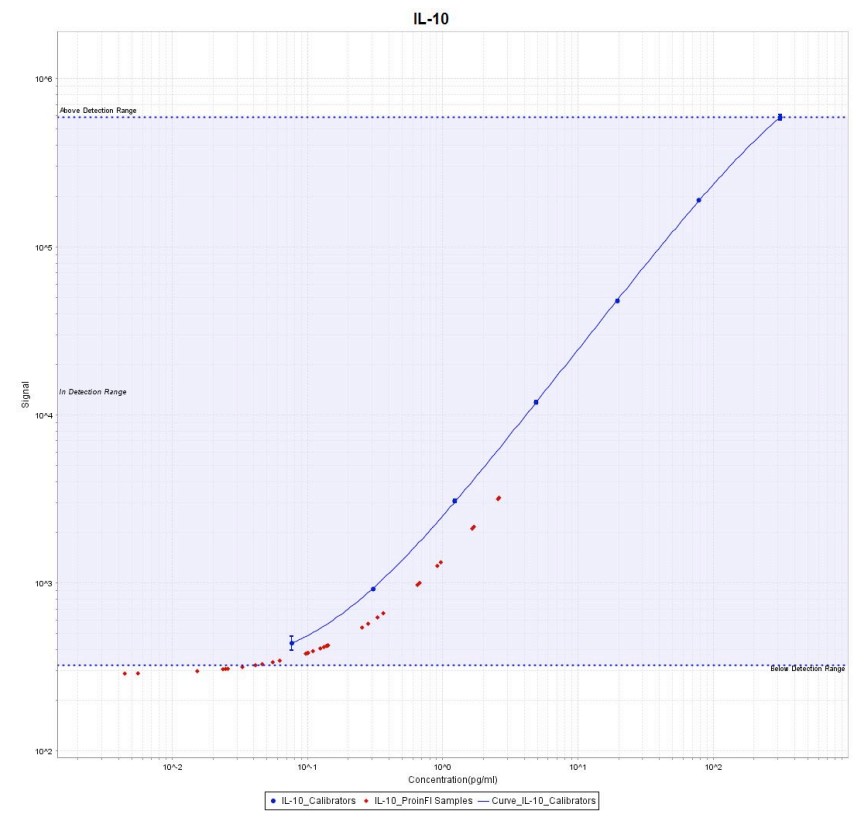

Figure 1b. Statistical Plot for Calculated Concentration Mean of IL-10

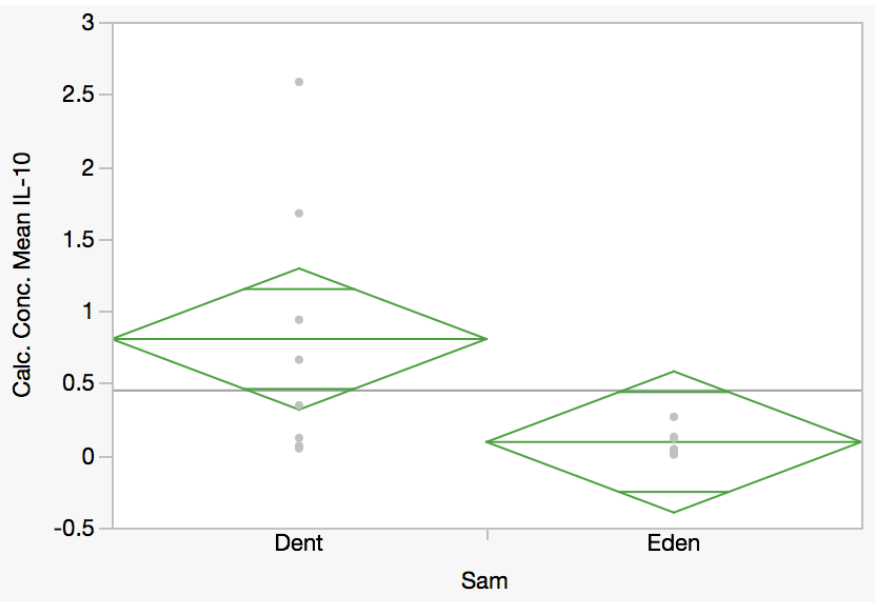




\section{Cytokine Markers}

A total of ten proinflammatory markers, including GM-CSF, IL-1 $\alpha$, IL-5, IL-7, IL-12/23 p40, IL-15, IL-16, IL-17A, TNF- $\beta$, and, VEGF, were tested in all sixteen subjects. Data for edentulous subjects is listed in Table 4 and data for dentate subjects is listed in Table 5. Similarly to above, if the quantitiy was undetectable, that sample was excluded from the measurements for that particular marker. The total amount of observations are listed in Table 6, followed by the total amount of DS and ES samples that were used for the analysis. For all markers, there was an overall higher level (pg/ml) of calculated concentration in DS than in ES subject groups, with exception to GM-CSF, which showed similar values. The highest mean response was $329.09 \mathrm{pg} / \mathrm{ml}$, by IL-1 $\alpha$, and the lowest mean reading was $0.042 \mathrm{pg} / \mathrm{ml}$, by TNF- $\beta$. Out of the ten markers that were tested, four of them showed a significant difference between DS and ES. The markers that showed significant differences are IL-12/23 p40 ( $p=0.042)$, IL-15 $(p=0.027), I L-1^{\alpha}(p=0.038)$, and VEGF $(p=0.010)$. 
Table 4: Calculated Concentration Means of Cytokine Markers for Edentulous Subjects (ES) $(\mathrm{pg} / \mathrm{ml})$

\begin{tabular}{|c|c|c|c|c|c|c|c|c|c|c|}
\hline - & GM-CSF & IL-12/23 p40 & IL-15 & IL-16 & IL-17A & IL-1 $\alpha$ & IL-5 & IL-7 & TNF- $\beta$ & VEGF \\
\hline ES 01 & - & 0.262 & 0.039 & 6.999 & - & 8.253 & 0.193 & 0.143 & 0.057 & 3.177 \\
\hline ES 02 & 0.672 & 0.413 & 0.049 & 39.756 & 0.237 & 35.308 & 0.135 & 0.061 & 0.013 & 15.874 \\
\hline ES 03 & 0.404 & 1.546 & 0.080 & 104.632 & 0.578 & 116.409 & 0.081 & 0.069 & 0.028 & 8.601 \\
\hline ES 04 & 0.245 & 2.777 & 0.068 & 104.052 & 0.339 & 187.790 & - & 0.145 & 0.033 & 69.314 \\
\hline ES 05 & 0.674 & 0.776 & 0.058 & 21.625 & - & 30.900 & 0.111 & 0.094 & 0.019 & 20.502 \\
\hline ES 06 & 1.151 & 1.648 & 0.062 & 59.341 & 0.315 & 105.885 & 0.040 & 0.053 & 0.028 & 36.638 \\
\hline ES 07 & 2.535 & 1.381 & 0.184 & 127.012 & 0.808 & 535.874 & 0.260 & 0.159 & 0.035 & 38.039 \\
\hline ES 08 & 0.510 & 0.941 & 0.032 & 49.768 & 0.110 & 49.374 & 0.109 & - & - & 15.657 \\
\hline Average & 0.885 & 1.218 & 0.071 & 64.148 & 0.398 & 133.724 & 0.133 & 0.103 & 0.031 & 25.975 \\
\hline Max & 2.535 & 2.777 & 0.184 & 127.012 & 0.808 & 535.874 & 0.260 & 0.159 & 0.057 & 69.314 \\
\hline Min & 0.245 & 0.262 & 0.032 & 6.999 & 0.110 & 8.253 & 0.040 & 0.053 & 0.013 & 3.177 \\
\hline
\end{tabular}

* Data in red indicates that the concentration was in detection range

Table 5: Calculated Concentration Means of Cytokine Markers for Dentate Subjects (DS) $(\mathrm{pg} / \mathrm{ml})$

\begin{tabular}{|c|c|c|c|c|c|c|c|c|c|c|}
\hline- & GM-CSF & IL-12/23 p40 & IL-15 & IL-16 & IL-17A & IL-1 $\boldsymbol{\alpha}$ & IL-5 & IL-7 & TNF- $\boldsymbol{\beta}$ & VEGF \\
\hline DS 09 & 0.726 & 1.402 & 0.085 & 60.781 & - & 86.750 & 0.071 & 0.106 & 0.008 & 16.295 \\
\hline DS 10 & 1.057 & 2.658 & 0.118 & 79.535 & 0.542 & 290.141 & 0.063 & 0.113 & 0.016 & 48.038 \\
\hline DS 11 & 1.314 & 1.211 & 0.187 & 122.273 & 0.203 & 219.027 & 0.165 & 0.172 & 0.029 & 64.624 \\
\hline DS 12 & 0.167 & 0.590 & 0.024 & 40.028 & 0.236 & 119.329 & 0.176 & 0.065 & - & 16.368 \\
\hline DS 13 & 1.037 & 4.075 & 0.301 & 471.159 & 8.860 & 1074.174 & 0.416 & 0.193 & 0.098 & 128.639 \\
\hline DS 14 & 0.370 & 1.334 & 0.102 & 43.593 & 0.494 & 204.372 & 0.196 & 0.092 & 0.051 & 35.907 \\
\hline DS 15 & 1.893 & 6.302 & 0.687 & 1077.091 & 4.071 & 2121.859 & 0.383 & 0.339 & 0.113 & 163.842 \\
\hline DS 16 & 0.358 & 0.886 & 0.063 & 60.283 & 0.325 & 80.022 & 0.162 & 0.102 & 0.052 & 40.929 \\
\hline Average & 0.865 & 2.307 & 0.196 & 244.343 & 2.104 & 524.459 & 0.204 & 0.148 & 0.052 & 64.330 \\
\hline Max & 1.893 & 6.302 & 0.687 & 1077.091 & 8.860 & 2121.859 & 0.416 & 0.339 & 0.113 & 163.842 \\
\hline Min & 0.167 & 0.590 & 0.024 & 40.028 & 0.203 & 80.022 & 0.063 & 0.065 & 0.008 & 16.295 \\
\hline
\end{tabular}

* Data in red indicates that the concentration was in detection range 
Table 6: ANOVA of Calculated Concentration Means of Cytokine Markers

\begin{tabular}{|c|c|c|c|c|c|c|}
\hline Marker & ES & DS & $\begin{array}{c}\text { Total } \\
\text { Observation }\end{array}$ & Mean of Response & F Ratio & P Values \\
\hline GM-CSF & 7 & 8 & 15 & 0.874292 & 0.0064 & 0.936765696 \\
\hline IL-12/23 p40 & 8 & 8 & 16 & 1.762653 & 4.4894 & $0.042497414^{\mathrm{a}}$ \\
\hline IL-15 & 8 & 8 & 16 & 0.13358 & 5.4016 & $0.027077091^{\mathrm{a}}$ \\
\hline IL-16 & 8 & 8 & 16 & 154.2455 & 4.1029 & 0.051785708 \\
\hline IL-17A & 6 & 7 & 13 & 1.316736 & 3.468 & 0.074854568 \\
\hline $\mathrm{IL}-1 \alpha$ & 8 & 8 & 16 & 329.0917 & 4.7382 & $0.037501293^{a}$ \\
\hline IL-5 & 7 & 8 & 15 & 0.170769 & 3.4843 & 0.072459589 \\
\hline IL-7 & 7 & 8 & 15 & 0.12714 & 3.1164 & 0.088411078 \\
\hline TNF- $\beta$ & 7 & 7 & 14 & 0.041494 & 4.0762 & 0.053914874 \\
\hline VEGF & 8 & 8 & 16 & 45.15263 & 7.5234 & $0.010174254^{\mathrm{a}}$ \\
\hline
\end{tabular}

${ }^{\mathrm{a}}$ Represents significant differences at the $\mathrm{P}<0.05$ interval (JMP/Pro Ver12, SAS Inst. Inc., Cary, NC).

Figure 2a. IL-12/23p40 Calculated Concentration Mean Plot (MSD Discovery Workbench 4.0)

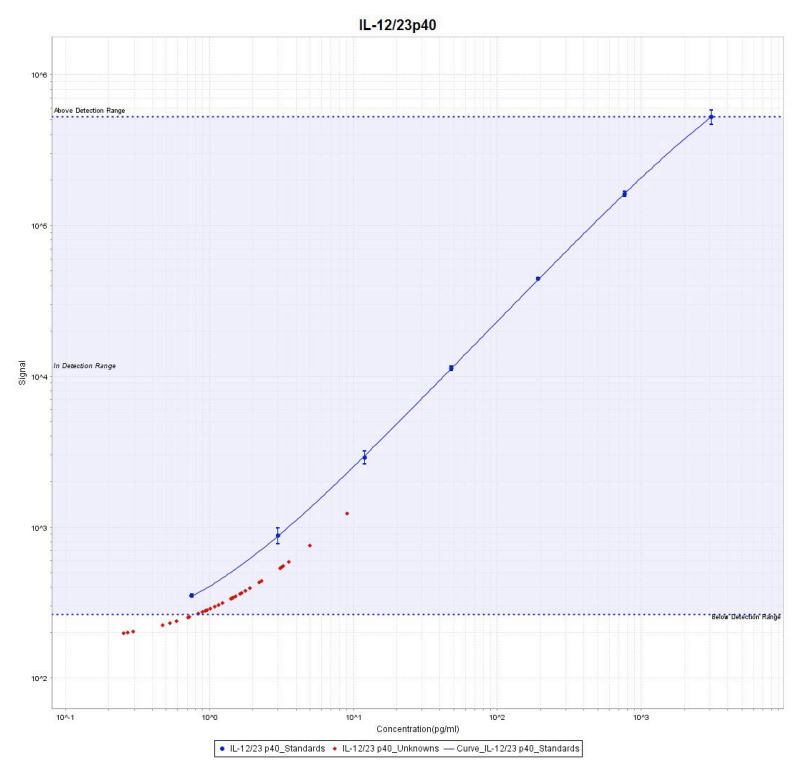


Figure 2b. Statistical Plot for Calculated Concentration Mean of IL-12/23p40

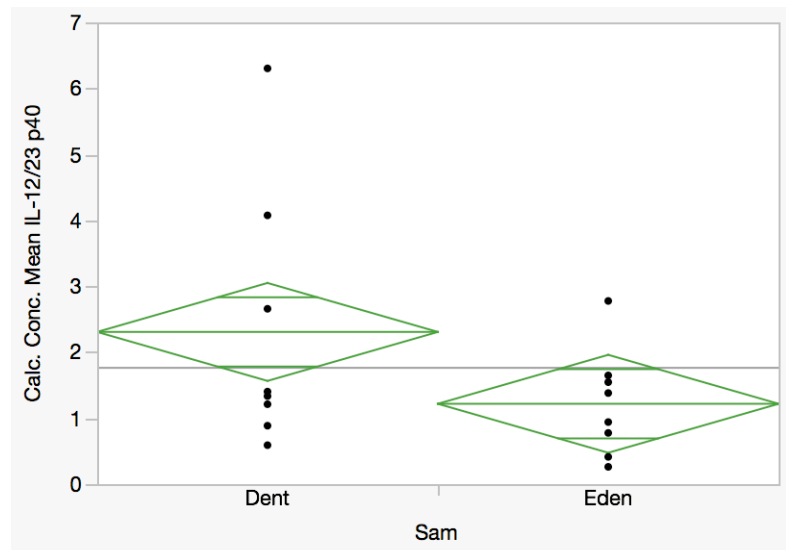

Figure 3a. IL-15 Calculated Concentration Mean Plot (MSD Discovery Workbench 4.0)

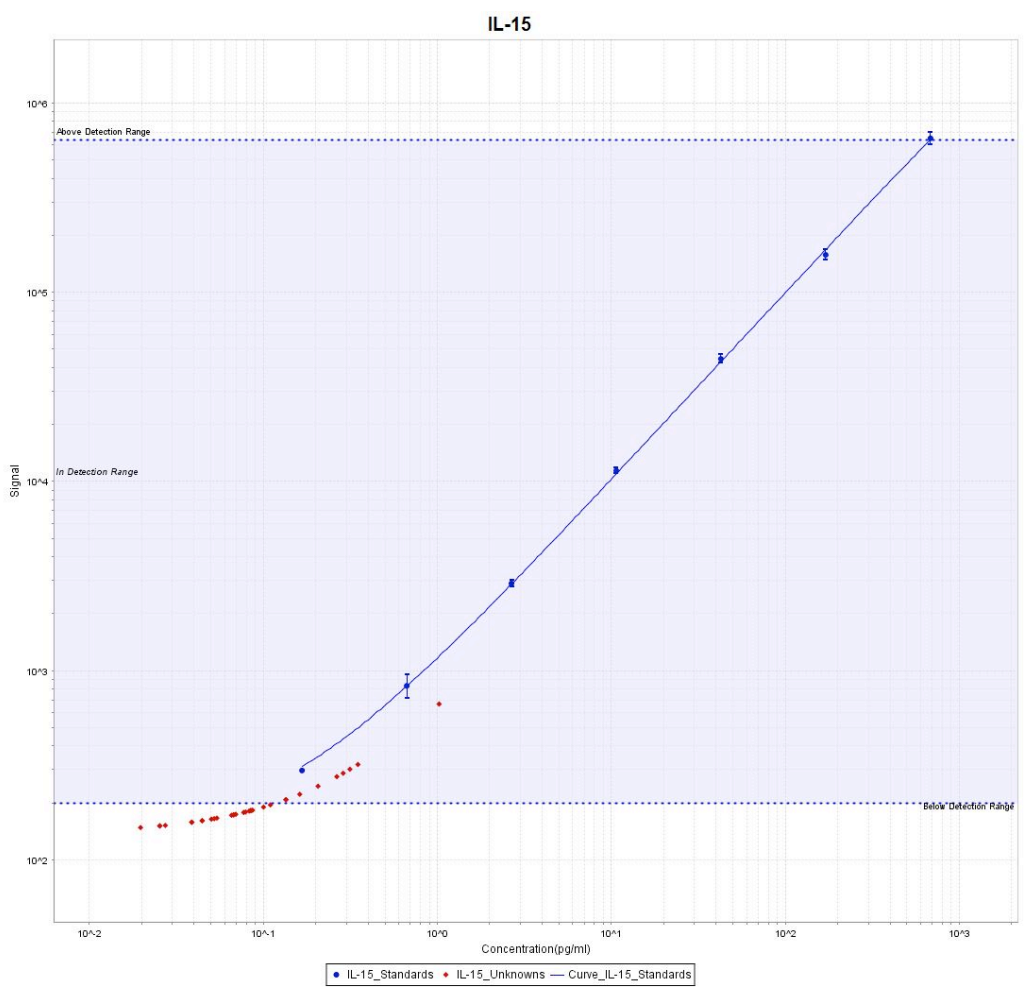


Figure 3b. Statistical Plot for Calculated Concentration Mean of IL-15

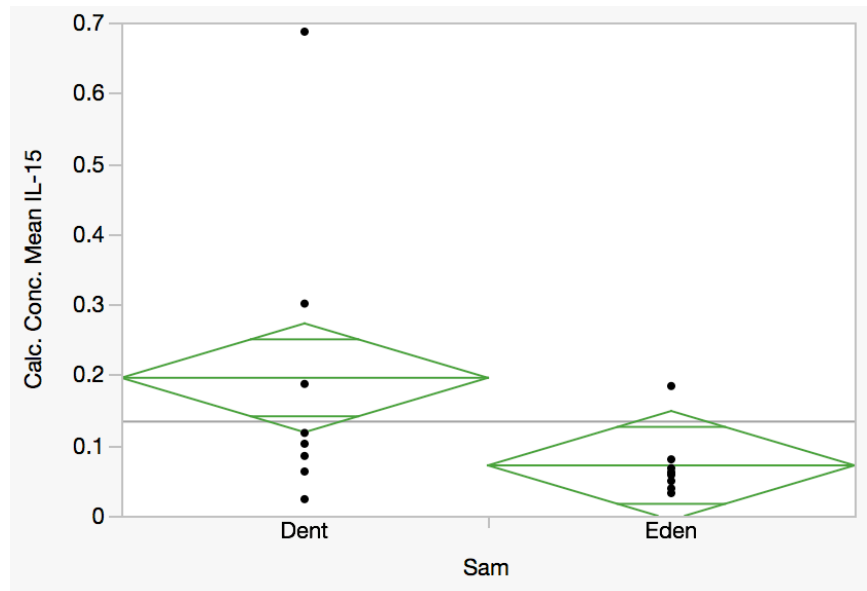

Figure 4a. IL-1 $\alpha$ Calculated Concentration Mean Plot (MSD Discovery Workbench 4.0)

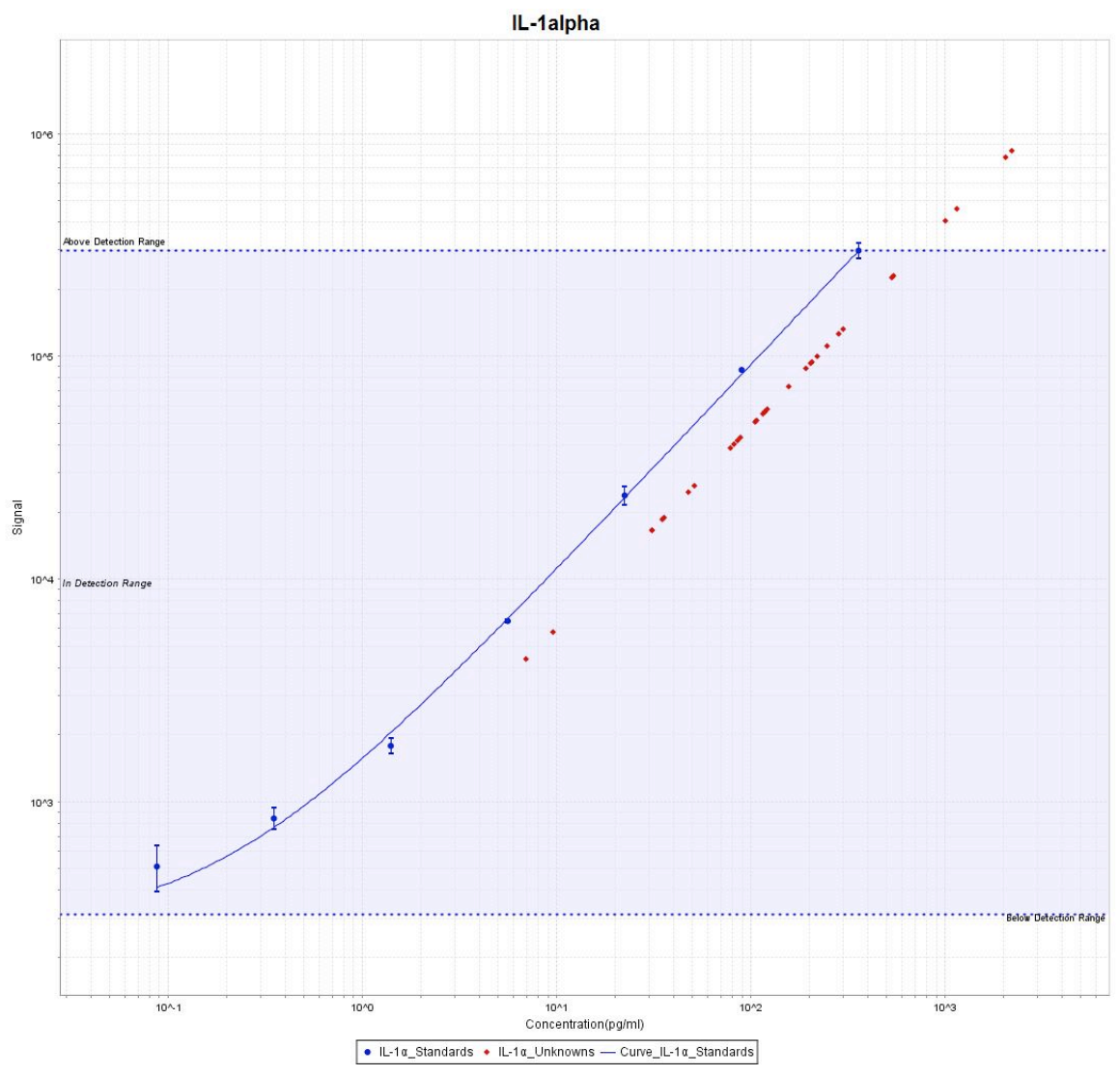


Figure 4b. Statistical Plot for Calculated Concentration Mean of IL-1 ${ }^{a}$

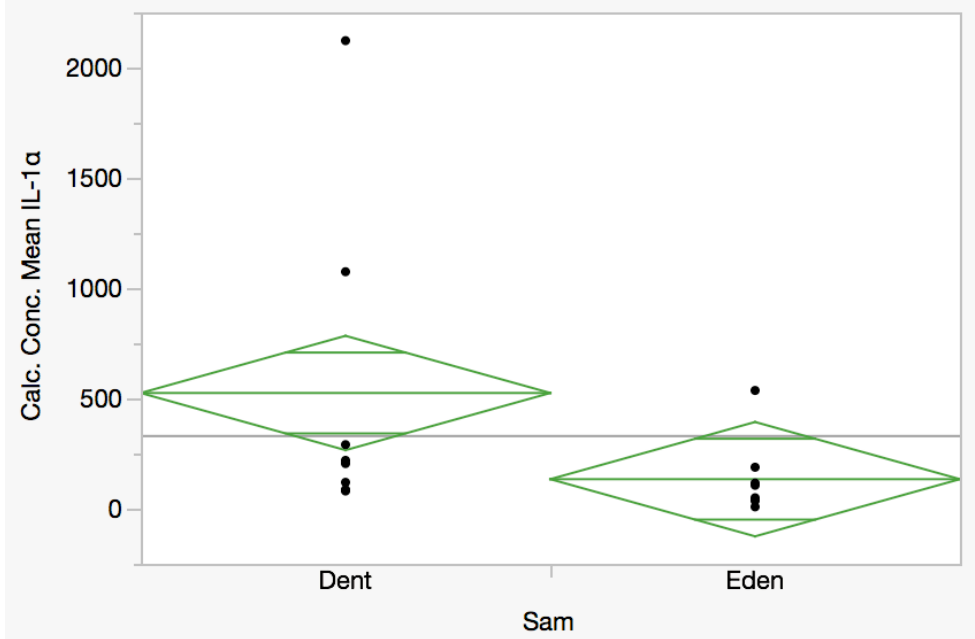

Figure 5a. VEGF Calculated Concentration Mean Plot (MSD Discovery Workbench 4.0)

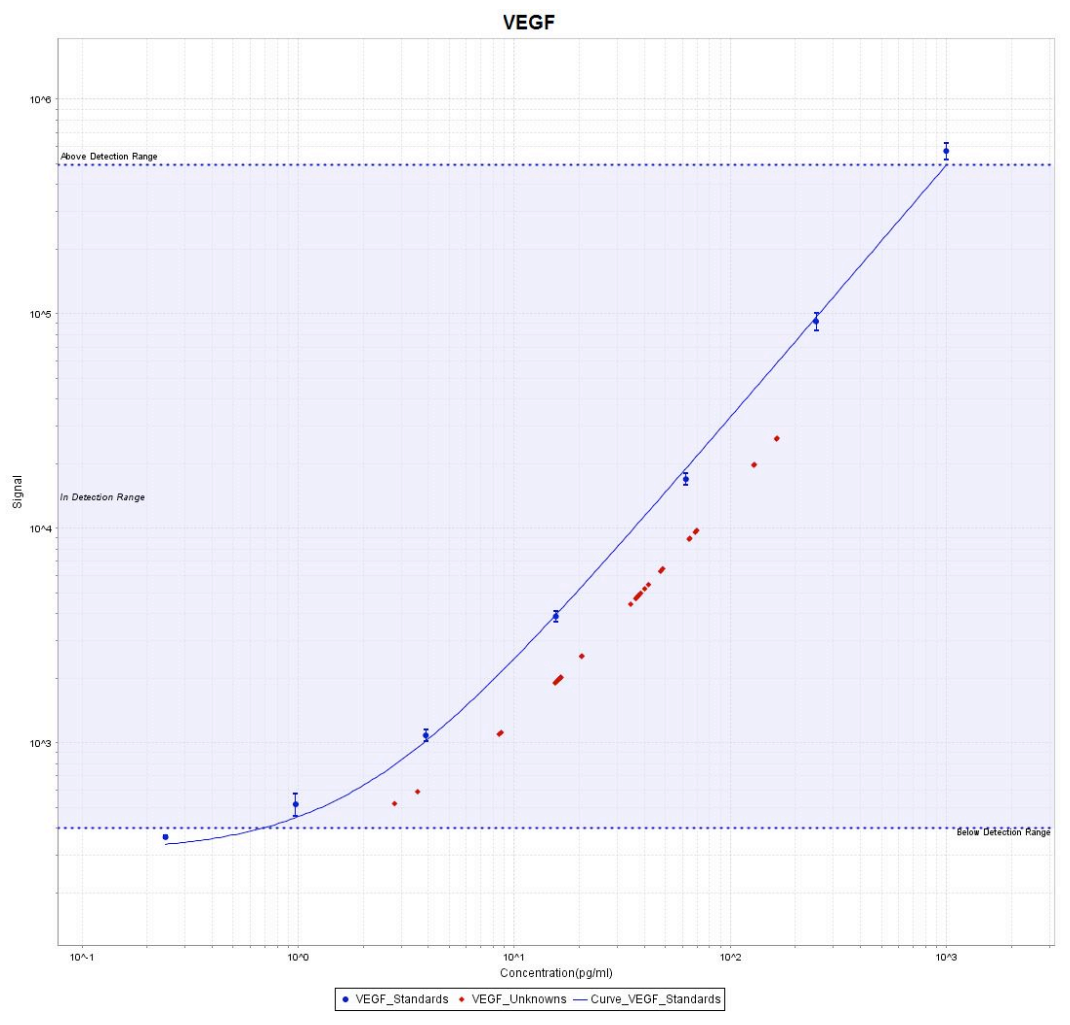

Figure 5b. Statistical Plot for Calculated Concentration Mean of VEGF 


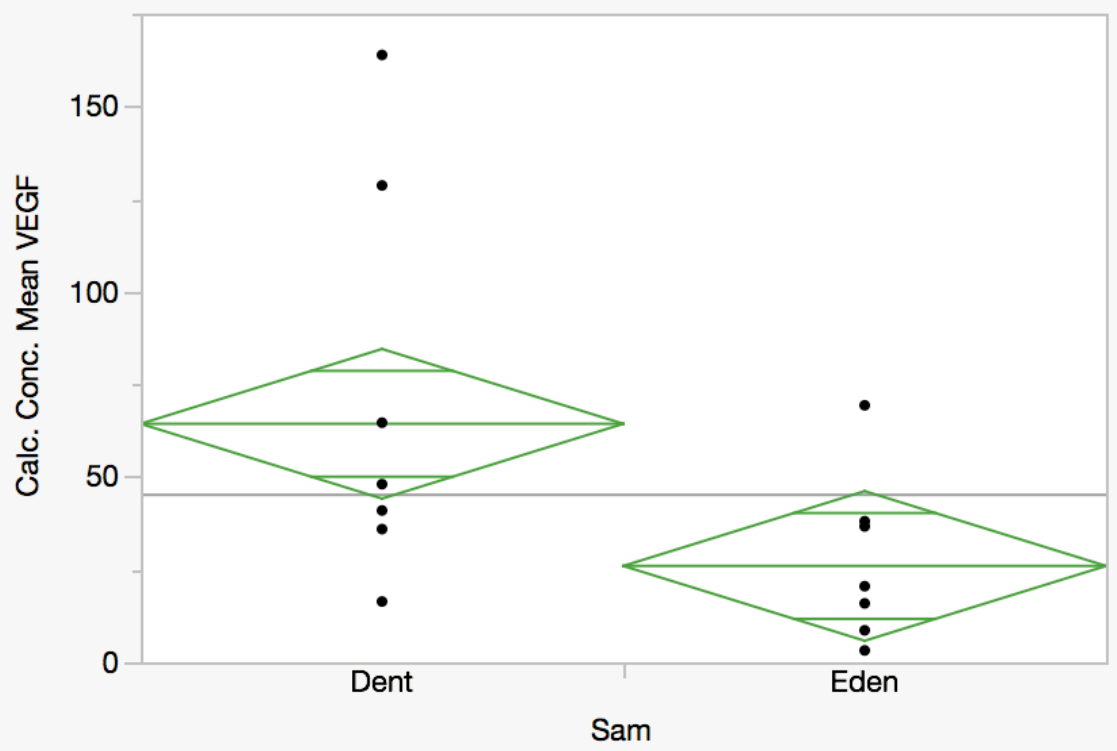




\section{Chapter V}

\section{DISCUSSION}

This current study is a pilot study to determine if MSD analysis is sensitive enough to determine the presence of significant differences between select cytokines in the peri-implant crevicular fluid of dentate versus edentulous patients that are restored with implants. The null hypothesis, that no significant differences in proinflammatory markers and cytokine markers in the peri-implant crevicular fluid of healthy implants when comparing implants in edentulous patients and implants in dentate patients, is rejected.

A total of twenty inflammatory marker levels were tested using MSD Mesoscale ELISA technology. These markers were divided into two groups - proinflammatory markers, including IFN- $\gamma$, IL-1 $\beta$, IL-2, IL-4, IL-6, IL-8, IL-10, IL-12p70, IL-13, and, TNF- $\alpha$, and cytokines, including GM-CSF, IL-1 $\alpha$, IL-5, IL-7, IL-12/23 p40, IL-15, IL-16, IL-17A, TNF- $\beta$, and, VEGF. These inflammatory markers were divided into groups of ten due to the limitation of the plates to hold 10 antibodies per well; thus, in order to incorporate twenty markers, two different 96 well, multi-spot plates were used. These cytokines were divided according to their cross-reactivity of the antibodies present on the plate. Out of the twenty markers, five of the levels in peri-implant crevicular fluid were significantly different between healthy edentulous patients and healthy dentate patients. Four of the five that were significantly different were in the cytokine group, which included IL-12/23 p40, IL-15, IL-1 $\alpha$, and VEGF, and one out of the five was in the proinflammatory group, which included IL-10.

Studies have shown that there are strong correlations between microflora of teeth

and dental implants ${ }^{2,68-72}$. It has also been shown that there is a strong correlation 
between the microflora that exists in the biofilms and the cytokine expression that is present $^{2,80,81}$. With these facts in mind, it raises the question whether or not fully edentulous patients restored with implants will have a significantly different inflammatory marker expression than implants that are surrounded by natural dentition. De Waal et al ${ }^{73}$ showed that there are higher pathogen-causing bacteria around partially dentate patients when compared to edentulous patients. Although previous studies have not investigated comparisons in the cytokine content in PICF between partially and fully edentulous patients, a hypothesis can be drawn stating that implants in partially dentate patients will have higher inflammatory responses. In this study, all inflammatory marker concentration totals were greater, in $\mathrm{pg} / \mathrm{ml}$, in the DS group than the ES group, except IL-4 and GM-CSF, which were essentially the same. Although all were not significantly different, the trend towards greater concentrations of inflammatory markers in dentate patients should be considered. These findings are supported by the literature when stating that crevicular fluid substituents of natural dentition have a heavy influence on peri-implant crevicular fluid and will have increased quantities due to the ability to colonize on hard tissues ${ }^{73,74,77-79}$.

When interpreting the data for statistical significance, no data was eliminated even if it was not determined to be within detection range. Due to this study being a pilot study, all information was considered useful in predicting whether or not significant enough data presented itself to warrant future studies. Although there is a considerable amount of data that is considered negligible by the MSD instrument, these small quantities still make statement concerning that particular cytokines role in PICF. This 
study was used to determine if MSD Mesoscale technology could be used for dental analysis of PICF measurements.

Due to this study being a pilot study, the small quantity of subjects makes it difficult to extrapolate the results to apply to a larger population. There are no correlations that were noted between the five cytokines to be significantly higher in dentate patients than in edentulous patients. They did not appear to be produced by the same cell, nor do they elicit similar responses.

Interleukin 12 plays a very important role in inflammation, more specifically, periodontal diseases. Although all subjects in this study were deemed healthy individuals, it could be indicative of early signs of bone loss. There is controversy in the literature about whether or not IL-12 is elevated in peri-implant diseases. Orozco et $a l^{84}$ found that there was no difference in IL-12 levels in inflamed states as compared to healthy levels ${ }^{84}$; meanwhile, Tsai et $a l^{44}$ determined that there were higher levels in diseased states. Future studies should be aimed to clarify the conflicting results from the previous studies mentioned.

Interleukin 10 has been reported as only found in the GCF of patients with periimplantitis. ${ }^{36}$ IL-10 was found in decreased levels in areas that tested positive to having bleeding on probing ${ }^{85}$. Yamazaki et al ${ }^{86}$ supported this by suggesting that IL-10 levels might be critical in immune regulation, controlling the balanace between innate inflammatory and acquired humoral responses ${ }^{87}$. This could support the findings of this study showing that IL-10 is elevated in patients that are dentate and restored with implants because even in healthy states, the body's immune system is fighting off pathogenic bacteria to a higher extent than edentulous patients due to the influence of 
hard-tissue pathogens. Due to the influence of neighboring microflora, the PICF may have a much more active immune mediators, rather than in patients where neighboring microflora from the dentition isn't creating the same immune reponse. Varying papers have shown that although IL-10 can be a determinant of inflammation ${ }^{36}$, it also acts as a constant regulator of the immune system whether healthy or diseased states are $\operatorname{present}^{87,88}$.

Vascular endothelial growth factor (VEGF) was shown to be higher in dentate patients than in edentulous patients restored with implants in this study. VEGF has demonstrated to be crucial in allowing inflammatory markers to reach a desired site. Nogueira-Filho ${ }^{82}$ displayed that lower levels of VEGF have been indicative of healthy gingival tissue. ${ }^{82}$ Booth $e t a l^{38}$ suggested that levels could be increased in patients with weakened healing ability, such as in elderly patients, hence systemic factors and overall immune system efficiency could have influenced a higher value. Due to lack of collection of demographic, Booth et al can not be supported in this paper. This fact supports the theory that although an implant may be clinically healthy, there may still be inflammation present ${ }^{9,41}$.

Interleukin 1 has been closely associated with bone loss in periodontitis ${ }^{50,51}$. Although closely related, IL-1 $\beta$ has been shown to be involved with more destruction, while Sakai $e t a l^{11}$ found that IL-1alpha along with TNF- $\alpha$ did not have any differences between healthy and diseased states. IL-1 $\alpha$ may have elevated levels due to depth of pocket $^{31}$ and was reported as a direct correlation between pocket depth and levels of IL$1 \alpha$. 
Interleukin-15 (IL-15) is produced by mononuclear cells and NK cells. They stimulate activated $\mathrm{B}, \mathrm{T}$ and $\mathrm{NK}$ cells and chemotaxis. Interleukin 15 has been shown to be high in inflammatory diseases, such as rheumatoid arthritis ${ }^{90}$. Buduneli et al ${ }^{91}$ stated that IL-15 may play a pivotal role in regulation of the leukocyte infiltrate. Due to its higher levels in the dentate patient, it could support that there is a constant regulation of immunity components is at a higher level due to presence of hard tissue pathogens existence in the PICF adjacent to teeth ${ }^{90}$.

The statistical differences in this study must be interpreted with caution. The results of this study are limited by its sample size. Since healthy sulci can have inflammatory markers, the constituents in the sulci are not just mere predictors of inflammation or bone loss but a combination of oral pathogens and the functional efforts of the patients' systemic immune system as a whole ${ }^{44,62}$. If a larger sample size is used, greater standardization cytokine levels that are present in a healthy individuals despite age, race, current medications, or pre-existing consitions. This leads to another limitation which is the lack of demographics collected. Although all patients were considered healthy, the patients could have had other pre-existing conditions that may have had an effect on the immune system in a minor but influencial way.

Peri-implant inflammation may be affected by local factors other than bacterial biofilms, such as implant system and location of the micro-gap ${ }^{10,82}$. In a future study, the implant manufacturers should be recorded and standardized to minimize any variables that could affect the results.

In addition, a limitation of this study could be the dilution of the sample in the TE Buffer. All samples were placed directly into $1-\mathrm{ml}$ of TE buffer, but only $0.4 \mathrm{ml}$ of 
solution was needed to run the appropriate samples. If less of the TE buffer was present in the vials, there is a possibility to have a more concentrated sample solution. The maufacturer recommended $1.0 \mathrm{ml}$ of TE buffer.

To the authors' knowledge, there has not been a study that evaluates the cytokines in the PICF of dentate patients restored with implants and edentulous patients restored with implants. This study showed that there are significant differences between edentulous and dentate cytokines. Further studies should perform this same study using a larger population. It would also be interesting to see if there are differences in the cytokines in PICF of dentate and edentulous patients in peri-implant disease states. 


\section{Chapter VI:}

\section{SUMMARY}

A total of twenty inflammatory marker levels were tested using MSD Mesoscale ELISA technology, including IFN- $\gamma$, IL-1 $\alpha$, IL-1 $\beta$, IL-2, IL-4, IL-5, IL-6, IL-7, IL-8, IL10, IL-12p70, IL-12/23 p40, IL-13, IL-15, IL-16, IL-17A, TNF- $\alpha$, TNF- $\beta$, GM-CSF, and, VEGF. Out of the twenty markers, five of the levels in peri-implant crevicular fluid were significantly different between healthy edentulous patients and healthy dentate patients. Four of the five that were significantly different were in the cytokine group, which included IL-12/23 p40, IL-15, IL-1 $\alpha$, and VEGF, and one out of the five was in the proinflammatory group, which included IL-10. The statistical differences in this study must be interpreted with caution. The results of this study are limited by its sample size. Since healthy sulci can have inflammatory markers, the constituents in the sulci are not just mere predictors of inflammation or bone loss but a combination of oral pathogens and the functional efforts of the patients' systemic immune system as a whole ${ }^{44,62}$.

\section{CONCLUSIONS}

1) There is a statistically significant difference between certain cytokines in PICF of dentate subjects compared to edentulous subjects.

2) There is a tendency towards higher levels of cytokines/inflammatory markers in PICF of implants in dentate patients compared to edentulous patients 


\section{REFERENCES}

1. Misch C. Contemporary implant dentistry. 3rd ed. St. Louis, MI: Mosby Elsevier; 2008.

2. Panagakos F, Aboyoussef H, Dondero R, Jandinski J. Detection and measurement of inflammatory cytokines in implant crevicular fluid. The International Journal of Oral and Maxillofacial Implants. 1996;11(6):794-799.

3. Meffert R, Langer B, Fritz M. Dental implants: A review. Journal of Periodontology. 1992;63:859-870.

4. Fonseca F, Junior M, Lourenco E, Teles D, Figueredo C. Cytokines expression in saliva and peri-implant crevicular fluid of patients with peri-implant disease. Clinical Oral Implant Research. 2014;25(2):68-72.

5. Stashenko P, Fujiyoshi P, Obernesser M, Prostak L, Haffajee A, Socransky S. Levels of interleukin 1 beta in tissue from sites of active periodontal disease. Journal of Clinical Periodontology. 1991;18:548-554.

6. Liskmann S, Vihalemm T, Salum O, Zilmer K, Fischer K, Zilmer M. Correlations between clinical parameters and interleukin-6 and interleukin-10 levels in saliva from totally edentulous patients with peri-implant disease. International Journal of Oral Maxillofacial Implants. 2006;4:543-550.

7. Murata M, Tatsumi J, Kato Y, et al. Osteocalcin, deoxypyridinoline and interluekin-1beta in peri-implant crevicular fluid of patients with peri-implantitis. Clinical Oral Implant Research. 2002;13:637-643.

8. Venza I, Visalli M, Cucinotta M, De Grazia G, Teti D, Venza M. Proinflammatory gene expression at chronic periodontitis and peri-implantitis sites in patients with or without type 2 diabeters. Journal of Periodontology. 2010;81:99-108. 
9. Nowzari H, Botero J, DeGiacomo M, Villacres M, Rich S. Microbiology and cytokine levels around healthy dental implants and teeth. Clinical Implant Dental Related Research. 2008;10:166-173.

10. Nowzari H, Phamduong S, Botero J, Villacres M, Rich S. The profile of inflammatory cytokines in gingival crevicular fluid around healthy osseointegrated implants. Clinical Implant Dental Related Research. 2012;14:546-552.

11. Sakai A, Ohshima M, Sugano N, Otsuka K, Ito K. Profiling the cytokines in gingival crevicular fluid using a cytokine antibody array. Journal of Periodontology. 2006;77:856-864.

12. Dursun E, Tozum T. Peri-implant crevicular fluid analysis, enzymes and biomarkers: A systemic review. Journal of Oral and Maxillofacial. 2016;7(3):1-12.

13. Li J, Wang H. Biomarkers associated with periimplant diseases. Implant Dentistry. 2014;23(5):607-611.

14. Rosen P, Clem D, Cochran D, et al. Peri-implant mucositis and peri-implantitis: A current understanding of their diagnoses and clinical implications. Journal of Periodontology. 2013;84(4):436-443.

15. The American Academy of Periodontology. Glossary of periodontal terms. Journal of Periodontology. 2001;4:1-53.

16. The glossary of prosthodontic terms. Journal of Prosthodontics. 2005;94(1):10-92.

17. Mombelli A, Lang N. The diagnosis and treatment of peri-implantitis. Periodontology 2000. $1998 ; 17: 63-76$.

18. Lindhe J, Meyle J. Peri-implant diseases: Consensus report of the sixth european workshop on periodon- tology. Journal of Clinical Periodontology. 2008;35(Supplemental 8):282-285. 
19. Sanz M, Chapple I. Clinical research on peri-implant diseases: Consensus report of working group 4. Journal of Clinical Periodontology. 2012;39(Supplemental 12):202-206.

20. Heitz-Mayfield L. Peri-implant diseases: Diagnosis and risk indicators. Journal of Clinical Periodontology. 2008;35(Suppl. 8):292-304.

21. Pontoriero R, Tonetti M, Carnevale G, Mombelli A, Nyman S, Lang N. Experimentally induced peri-implant mucositis. A clinical study in humans. Clinical Oral Implant Research. $1994 ; 5: 254-259$.

22. Salvi G, Aglietta M, Eick S, Sculean A, Lang N, Ramseier C. Reversibility of experimental peri-implant mucositis compared with experimental gingivitis in humans. Clinical Oral Implant Research. 2012;23:182-190.

23. Javed F, Al-Hezaimi K, Salameh Z, Almas K, Romanos G. Proinflammatory cytokines in the crevicular fluid of patients with peri-implantitis. Cytokine. 2011;53:8-12.

24. Duarte P, de Mendonca A, Maximo M, Santos V, Bastos M, Nociti Junior F. Differential cytokine expressions affect the severity of peri-implant disease. Clinical Oral Implant Research. 2009;20:514-520.

25. Van der Weijden G, van Bemmel K, Renvert S. Implant therapy in partially edentulous, periodontally compromised patients: A review. Journal of Clinical Periodontology. 2005;32:506511.

26. Karoussis I, Kotsovilis S, Fourmousis I. A comprehensive and critical review of dental implant prognosis in periodontally compromised partially edentulous patients. Clinical Oral Implant Research. 2007;18:669-679. 
27. Schou S, Holmstrup P, Worthington H, Esposito M. Outcome of implant therapy in patients with previous tooth loss due to periodontitis. Clinical Oral Implant Research. 2006;17(Supplemental 2):104-123.

28. Male D, Brostoff J, Roth D, Roitt,. Immunology. 7th ed. London, UK: Mosby Elsevier; 2006.

29. Riis J, Out D, Dorn L, et al. Salivary cytokines in healthy adolescent girls: Intercorrelations, stability and associations with serum cytokines, age, and pubertal stage. Developmental Psychobiology. 2013;56(4):797-811.

30. Lamont R, Burne R, Lantz M, LeBlanc D. Oral and microbiology and immunology. 1st ed. Ann Arbor, MI: American Society for Microbiology Press; 2006.

31. Masada M, Persson R, Kenny J, Lee S, Page R, Allison A. Measurement of interleukin - $1 \alpha$ and $1 \beta$ in gingival crevicular fluid: Implications for the pathogenesis of periodontal disease. Journal of Periodontal Research. 1990;25:156-163.

32. Kabashima H, Nagata K, Hashiguchi I. Interleukin-1 receptor antagonist and interleukin-4 in gingival crevicular fluid of patients with inflammatory periodontal disease. Journal of Oral Pathology Medicine. 1996;25:449-455.

33. Geivelis M, Turner D, Peterson E, Lambert B. Measurements of interleukin-6 in gingival crevicular fluid from adults with destructive periodontal disease. Journal of Periodontology. $1993 ; 64: 980-983$.

34. Fitzgerald J, Kreutzer D. Localization of interleukin-8 in human gingival tissues. Oral Microbiology and Immunology. 1995;10:297-303. 
35. Tonetti M, Freiburghaus K, Lang N, Bickel M. Detection of interleukin-8 and matrix metalloproteinases transcripts in healthy and diseased gingival biopsies by RNA/PCR. Journal of Periodontal Research. 1993;28:511-513.

36. Gamonal J, Acevedo A, Bascones A, Jorge O, Silva A. Levels of interleukin-1 beta, -8, and 10 and RANTES in gingival crevicular fluid and cell populations in adult periodontitis patients and the effect of periodontal treatment. Journal of Periodontology. 2000;71:1535-1545.

37. Florentino D, Bond M, Mosmann T. Two types of mouse helper T cell. IV. Th2 clones secret a factor that inhibits cytokine production by Th1 clones. Journal of Experimental Medicine. 1989; 170:2081-2095.

38. Booth V, Young S, Cruchley A, Taichman N, Paleolog E. Vascular endothelia growth factor in human periodontal disease. Journal of Periodontal Research. 1998;33:491-499.

39. Connolly D, Olander J, Heuvelman D. Human vascular permeability factor. isolation from U937 cells, Journal of Biological Chemistry. 1989;264(20):017-024.

40. Tsai C, Ku C, Ho K, Wu Y, Hung C. Changes in gingival crevicular fluid in interleukin-4 and interferon-gamma in patients with chronic periodontitis before and after periodontal initial therapy. Journal of Medical Science. 2007;23(1):1-7.

41. Ejeil A, Gaultier F, Igondio-Tchen S. Are cytokines linked to collagen breakdown during periodontal disease progression? Periodontology 2000. 2004;35:75-100.

42. Dixon D, Bainbridge B, Darveau R. Modulation of the innate immune response within the periodontium. Periodontology 2000. 2004;35:53-74. 
43. Chang Y, Yang S, Lai C, Liu J, Hsieh Y. Regulation of matrix metalloproteinase production by cytokines, pharmacological agents and periodontal pathogens in human periodontal ligament fibroblast cultures. Journal of Periodontal Research. 2002;37:196-203.

44. Teles R, Sakellari D, Teles F. Relationships among gingival crevicular fluid biomarkers, clinical parameters of periodontal disease, and the subgingival microbiota. Journal of Periodontology. 2010;81:89-98.

45. Zhang J, Kashket S, Lingstrom P. Evidence for the early onset of gingival inflammation following short-term plaque accumulation . Journal of Clinical Periodontology. 2002;29:10821085.

46. Matsuki Y, Yamamoto T, Hara K. Detection of inflammatory cytokine messenger RNAexpressing cellsin human inflamed gingiva by combined in situ hybridization and immunohistochemistry. Immunology. 1992;76:42-47.

47. Matsuki Y, Yamamoto T, Hara K. Interleukin-1 mRNA-expressing macrophages in human chronically inflamed gingival tissues. American Journal of Pathology. 1991;138(1):1299-1305.

48. di Giovine F, Poole S, Situnayake R, Wadhwa M, Duff G. Absence of correlation between indices of systemic inflammation and synovial fluid interleukin 1 (alpha and beta) in rheumatic diseases. Rheumatology International. 1990;2:259-264.

49. Murray R, Kay J, Sangermani D, Stow J. A role for the phagosome in cytokine secretion. Science. 2005;310:1492-1495.

50. Martin T, Romas E, Gillespie M. Interleukins in the control of osteoclast differentiation. Critical Reviews in Eukaryotic Gene Expression. 1998;8:107-123. 
51. Horowitz J, Lorenzo J. Local regulators of bone: IL-1, TNF, lymphotoxin, interferon- $\gamma$, IL-8, IL-10, IL-4, the LIF/IL-6 family, and additional cytokines. In: Bilezikian J, Raisz L, Rodan G, eds. Principles of bone biology. 2nd ed. San Diego, CA: Academic Press; 2002:961-978.

52. Page R, Schroeder H. Pathogenesis of inflammatory periodontal disease: A summary of current work. Laboratory Investigation. 1976;33:235-249.

53. Mathur A, Yang C, Wolff L. Cytokines in gingival crevicular fluid of periodontally diseased and healthy sites. Journal of Periodontal Research. 1995;31:489-495.

54. Tsai C, Ho Y, Chen C. Levels of interleukin-1 $\beta$ and interleukin-8 in gingival crevicular fluids in adult periodontitis. Journal of Periodontology. 1995;66:852-859.

55. Payne J, Reinhart R, Masada M, DuBois L, Allison A. Gingival crevicular fluid IL-8: Correlation with local IL-1 $\beta$ levels and patient estrogenous status. Journal of Periodontal Research. 1993;28:451-453.

56. Hou R, Goloubeva O, Neuberg D, Strominger J, Wilson S. Interleukin-12 and interleukin-2induced invariant natural killer T-cell cytokine secretion and perforin expres- sion independent of T-cell receptor activation. Immunology. 2003;110:30-37.

57. Baggiolini M, Walz A, Kunkel S. Neutrophil-activating peptide-1/interleukin 8, a novel cytokine that activates neutrophils. Journal of Clinical Investigation. 1989;84:1045-1049.

58. Offenbacher S. Periodontal disease: Pathogenesis. Annals Periodontology. 1996;1:821-878.

59. Birkedal-Hansen H. Role of cytokines and inflammatory mediators in tissue destruction. Journal of Periodontal Research. 1993;28:500-510.

60. Yamazaki K, Nakajima N. Antigen specificity and T cell clonality in periodontal disease. Periodontology 2000. 2004;35:75-100. 
61. Dorland's illustrated medical dictionary. 32nd ed. Philadelphia, PA, USA: Elsevier Saunders; 2012.

62. Newman M, Takei H, Klokkevold P, Carranza F. Chapter 6: Defense mechanisms of the gingiva. In: Carranza's clinical periodontology. 11th ed. St. Louis, MI: Elsevier Saunders; 2006:66-70.

63. Brill N, Krasse B. The passage of tissue fluid into the clinically healthy gingival pocket. Acta Odontologica Scandinavica. 1968;16:223.

64. Challacombe S. Passage of serum immunoglobulins into the oral cavity. In: Lehmer T, Cimasoni G, eds. Borderland between caries and periodontal disease. Vol. 2 ed. London: Academic Press; 1980.

65. Bevilacqua L, De Biasi M, Lorenzon M, Frattini C, Angerame D. Volumetric analysis of gingival crevicular fluid and peri-implant sulcus fluid in healthy and diseased sites: A crosssectional split-mouth pilot study. The Open Dentistry Journal. 2016;10:131-138.

66. Cadosch D, Chan E, Gautschi O, Filgueira L. Metal is not inert: Role of metal ions released by biocorrosion in aseptic loosening - current concepts. Journal of Biomedical Materials Research. 2009;91:1252-1262.

67. Perala D, Chapman R, Gelfand J, Callahan M, Adams D, Lie T. Relative production of IL-1 $\beta$ and TNF- $\alpha$ by mononuclear cells after exposure to dental implants. Journal of Periodontology. 1992;63:426-430.

68. Papaioannou W, Quirynen M, van Steenberghe D. The influence of periodontitis on the subgingival flora around implants in partially edentulous patients. Clinical Oral Implant Research. 1996;7:405-409. 
69. Máximo M, de Mendonça A, Alves J, Cortelli S, Peruzzo D, Duarte P. Peri-implant diseases may be associated with increased time loading and generalized periodontal bone loss: Preliminary results. Journal of Oral Implantology. 2008;34:268-273.

70. Hardt C, Gröndahl K, Lekholm U, Wennström J. Outcome of implant therapy in relation to experienced loss of periodontal bone support: A retrospective 5- year study. Clinical Oral Implant Research. 2002;13:488-494.

71. Mombelli A., van Osten M, Church E, Lang N. The microbiota associated with successful and failing osseointegrated titanium implants. Oral Microbiology and Immunology. 1987;2:145-152.

72. Malstrom H, Fritz M, Timmis D, Van Dyke T. Osseointegrated treatment of a patient with rapidly progressive periodontitis: A case report. Journal of Periodontology. 1990;61:300-304.

73. de Waal Y, Winkel E, Meijer H, Raghoebar G, van Winkelhoff A. Differences in peri-implant microflora between fully and partially edentulous patients: A systematic review. Journal of Periodontology. 2014;85(1):68-82.

74. Socransky S, Haffajee A. Periodontal microbial ecology. Periodontology 2000. 2005;38:135187.

75. Van Assche N, Van Essche M, Pauwels M, Teughels W, Quirynen M. Do periodontaopathogens disappear after full-mouth tooth extraction? Journal of Clinical Periodontology. 2009;36:1043-1047.

76. Devides S, Franco A. Evaluation of peri-implant microbiota using the polymerase chain reaction in completely edentulous patients before and after placement of implant-supported prostheses submitted to immediate load. International Journal of Oral Maxillofacial Implants. 2006;21:262-269. 
77. Leonhardt A, Adolfsson B, Lekholm U, Wikström M, Dahlen G. A longitudinal microbiological study on osseointegrated titanium implants in partially edentulous patients. Clinical Oral Implant Research. 1993;4:113-120.

78. Lekholm U, Ericsson I, Adell R, Slots J. The condition of the soft tissues at tooth and fixture abutments supporting fixed bridges. A microbiological and histological study. Journal of Clinical Periodontology. 1986;13:558-562.

79. Mombelli A, Marxer M, Gaberthuel T, Grunder U, Lang N. The microbiota of osseointegrated implants in patients with a history of periodontal disease. Journal of Clinical Periodontology. 1995;22:124-150.

80. Jandinski J, Stashenko P, Feder L, et al. Localization of interleukin-1 $\beta$ in human periodontal tissue. Journal of Periodontology. 1991;62:36-43.

81. Stashenko P, Jandinski J, Fujiyoshi P, Rynar J, Socransky S. Tissue levels of bone resorptive cytokines in periodontal disease. Journal of Periodontology. 1991;62:504-509.

82. Nogueira-Filho G, Pesun I, Isaak-Ploegman C, Wijegunasinghe M, Wierzbicki T, McCulloch C. Longitudinal comparison of cytokines in per-implant fluid and gingival crevicular fluid in healthy mouths. Journal of Periodontology. 2014;85(11):1582-1588.

83. Curtis D, Kao R, Plesh O, Finzen F, Franz L. Crevicular fluid analysis around two failing dental implants: A clinical report. Journal of Prosthodontics. 1997;6:210-214.

84. Orozco A, Gemmell E, Bickel M, Seymour G. Interleukin-1beta, interleukin-12 and interleukin-18 levels in gingival fluid and serum of patients with gingivitis and periodontitis. Oral Microbiology and Immunology. 2006;21:256-260. 
85. Hirose M, Ishihara K, Saito A, Nakagawa T, Yamada S, Okuda K. Expression of cytokines and inducible nitric oxide synthase in inflamed gingival tissue. Journal of Periodontology. 2001;72:590-597.

86. Yamazaki K, Tabeta K, Nakajima T, et al. Interleukin-10 gene promoter polymorphism in japanese patients with adust and early-onset periodontitis. Journal of Clinical Periodontology. 2001;28:828-832.

87. Goutoudi P, Diza E, Arvanitidou M. Effect of periodontal therapy on crevicular fluid interleukin-1 beta and interleukin-10 levels in chronic periodontitis. Journal of Dentistry. 2004;32:511-520.

88. Yaghobee S, Khorsand A, Paknejad M. Comparison of interleukin-1b levels in gingival crevicular fluid and peri-implant crevicular fluid and its relationship with clinical indexes. Journal of Dentistry. 2013;10:1-9.

89. Cooper L. Objective criteria: Guiding and evaluating dental implant esthetics. Journal of Complication. 2008;20(3):195-205.

90. Bulfone-Paus S, Ungureanu D, Pohl T. Interleukin-15 protects from lethal apoptosis in vivo. Natural Medicine Journal. 1997;3:1124-1128.

91. Buduneli E, Genel F, Atilla G, Kutukculer N. Evaluation of p53, bcl-2, and interleukin-15 levels in gingival crevicular fluid of cyclosporin A-treated patients. Journal of Periodontology. 2003;74(4):506-511.

\section{Curriculum Vitae}

Paul Canallatos, D.D.S. 
2201 Hayden Lane, Morgantown, WV 26505 | (516) 680-7368|

pacanallatos@mix.wvu.edu

\section{EDUCATION}

West Virginia University, Morgantown, WV

[M.S. in Prosthodontics]- expected graduation May 2017

2014-Present

State University of New York at Buffalo School of Dental Medicine, Buffalo, NY

Implant Fellowship Certificate

2013-2014

Roswell Park Cancer Institute, Buffalo, NY

General Practice Residency Certificate

$2012-2013$

State University of New York at Buffalo School of Dental Medicine, Buffalo, NY

Doctor of Dental Surgery

2008-2012

Summa Cum Laude

State University of New York at Buffalo, Buffalo, NY

B.S. in Biomedical Sciences

2004-2008

\section{MEMBERSHIPS}

American Association of Maxillofacial Prosthetics

American Cleft Palate-Craniofacial Association

American College of Prosthodontists

American Dental Association

Academy of Osseointegration 
Delta Sigma Delta

\section{LANGUAGES}

[English - native language]

Figure 6a. GM-CSF Calculated Concentration Mean Plot (MSD Discovery Workbench 4.0)

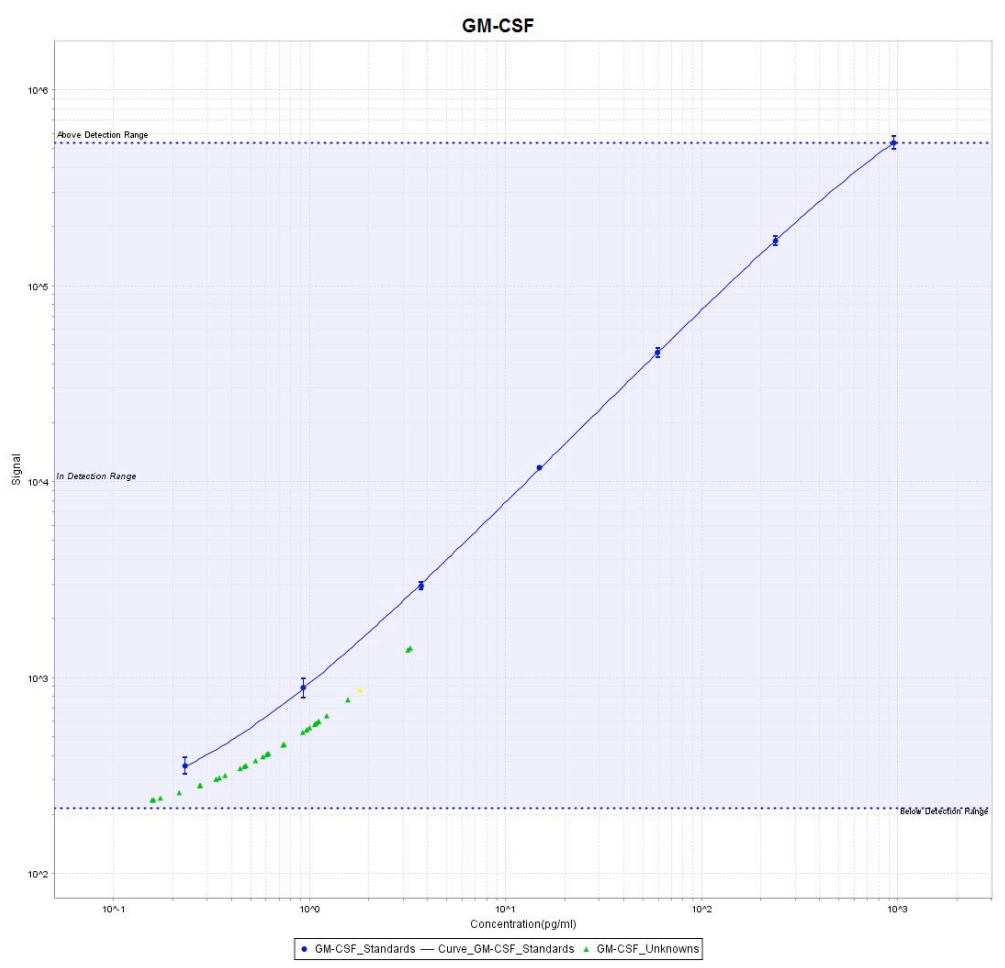

Figure 6b. Statistical Plot for Calculated Concentration Mean of GM-CSF 


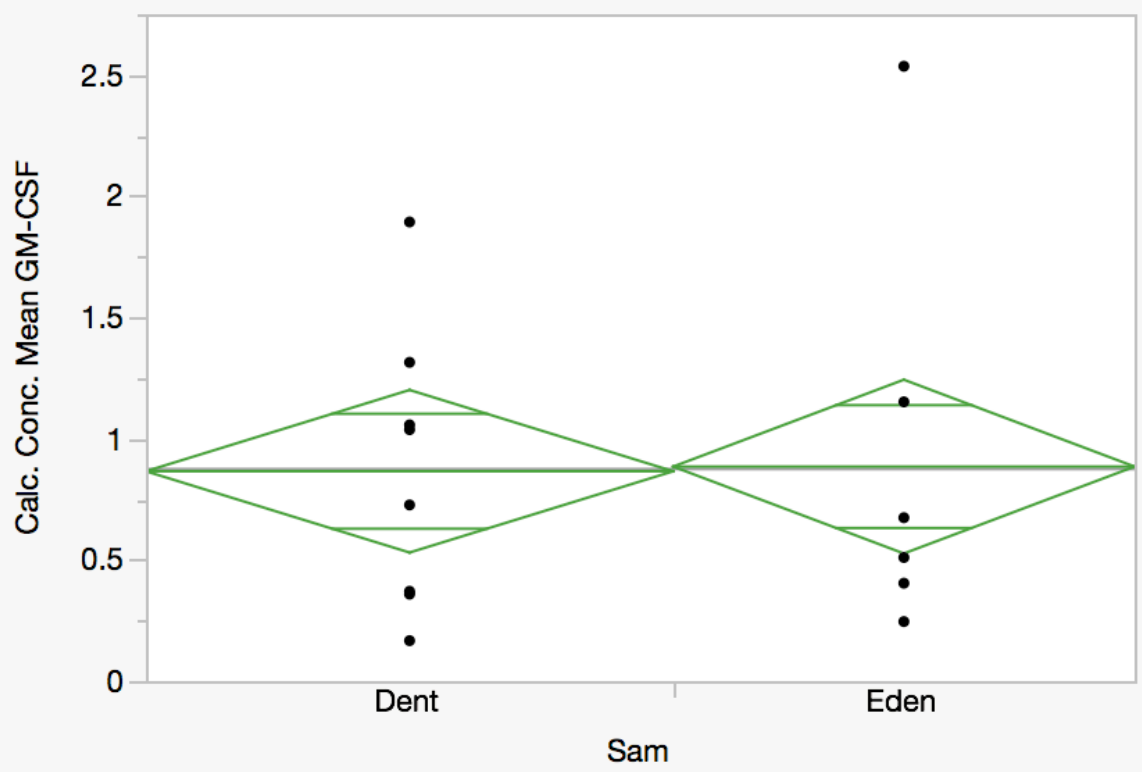

Figure 7a. IFN- $\gamma$ Calculated Concentration Mean Plot (MSD Discovery Workbench 4.0)

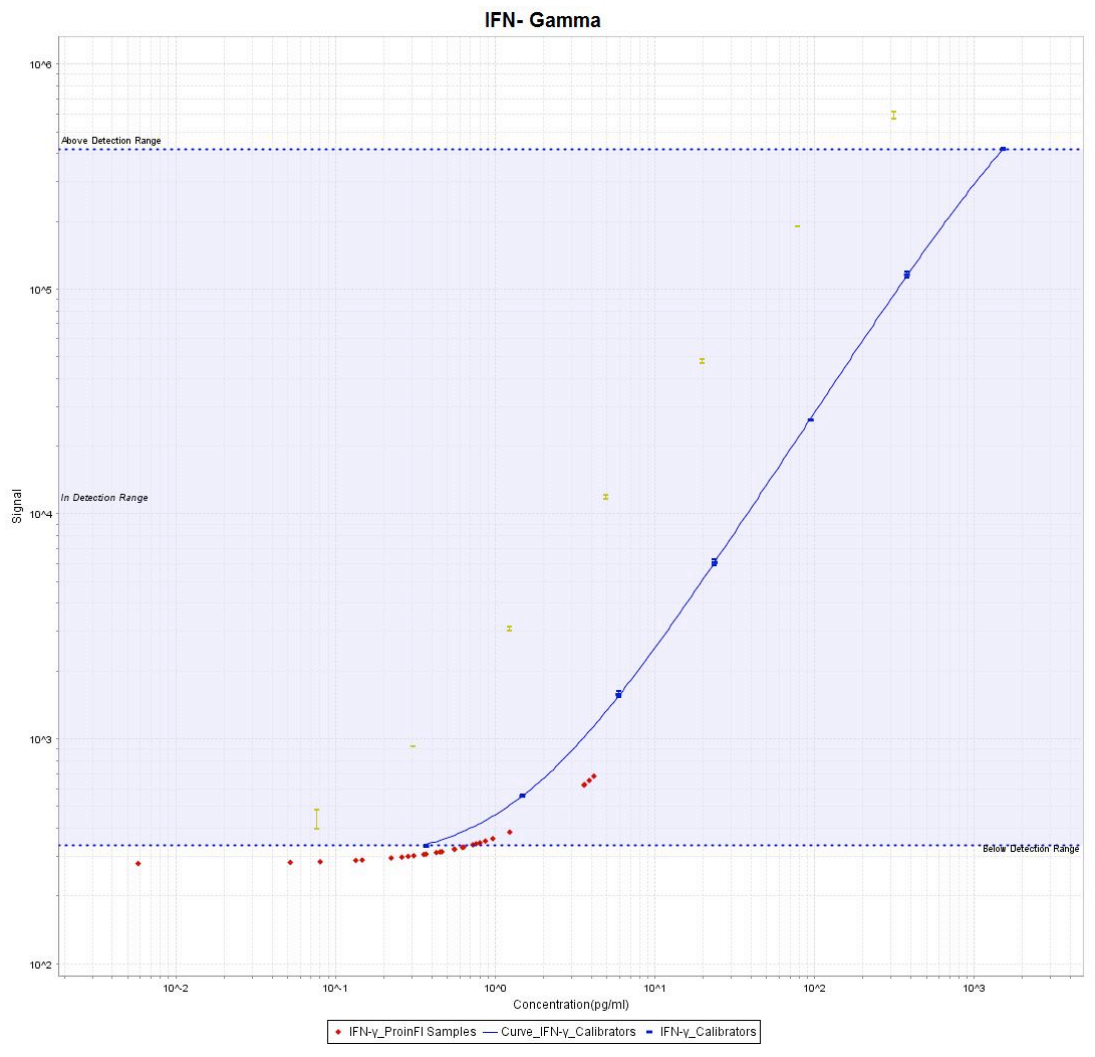

Figure 7b. Statistical Plot for Calculated Concentration Mean of IFN- $\gamma$ 


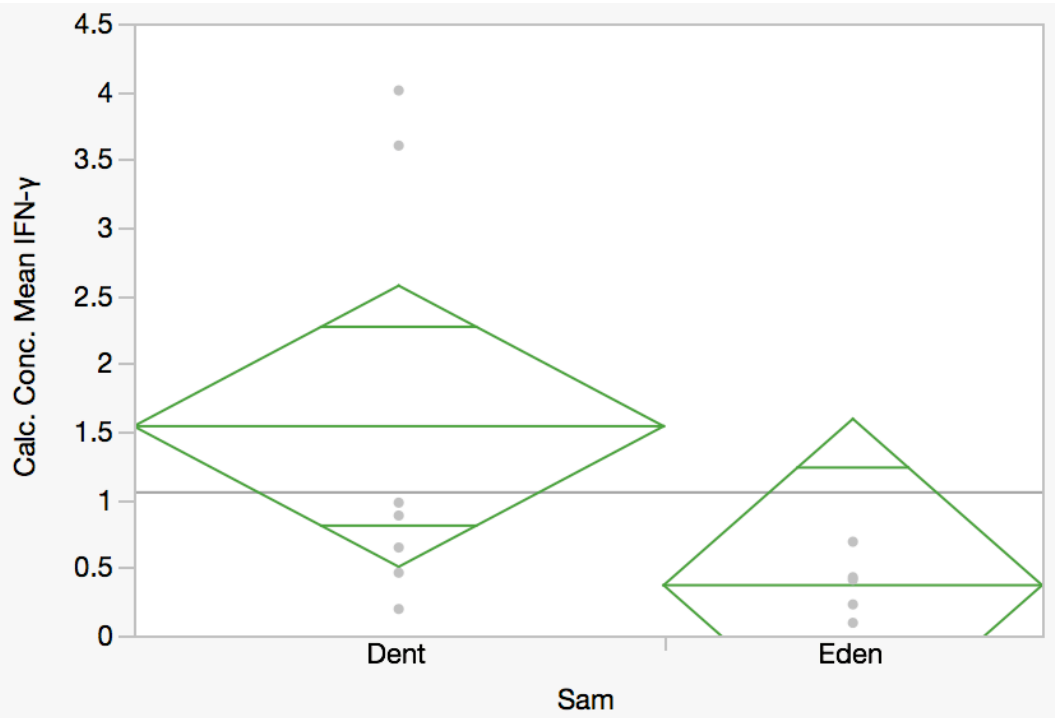

Figure 8a. IL-1ß Calculated Concentration Mean Plot (MSD Discovery Workbench 4.0)

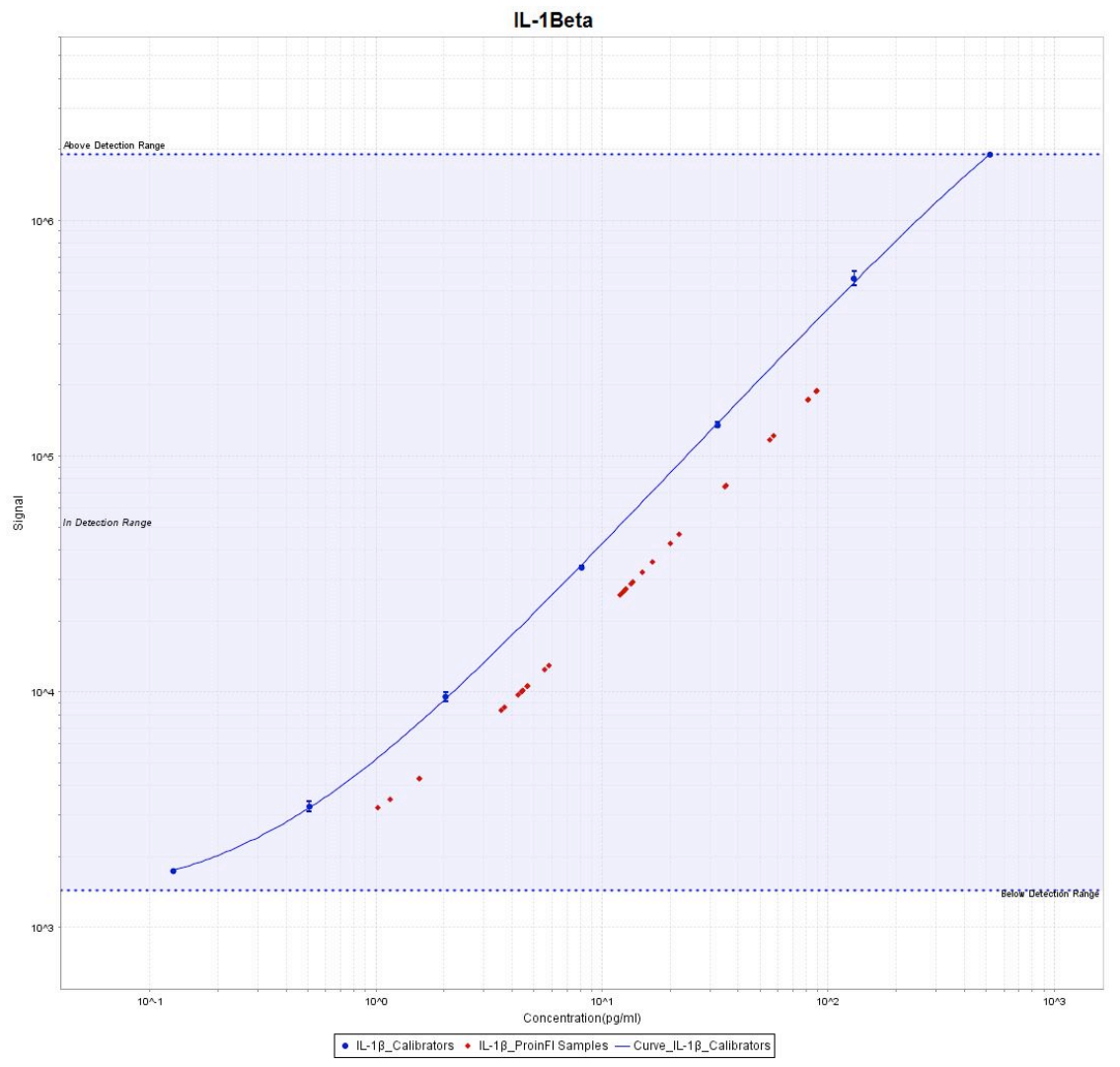

Figure 8b. Statistical Plot for Calculated Concentration Mean of IL-1及 


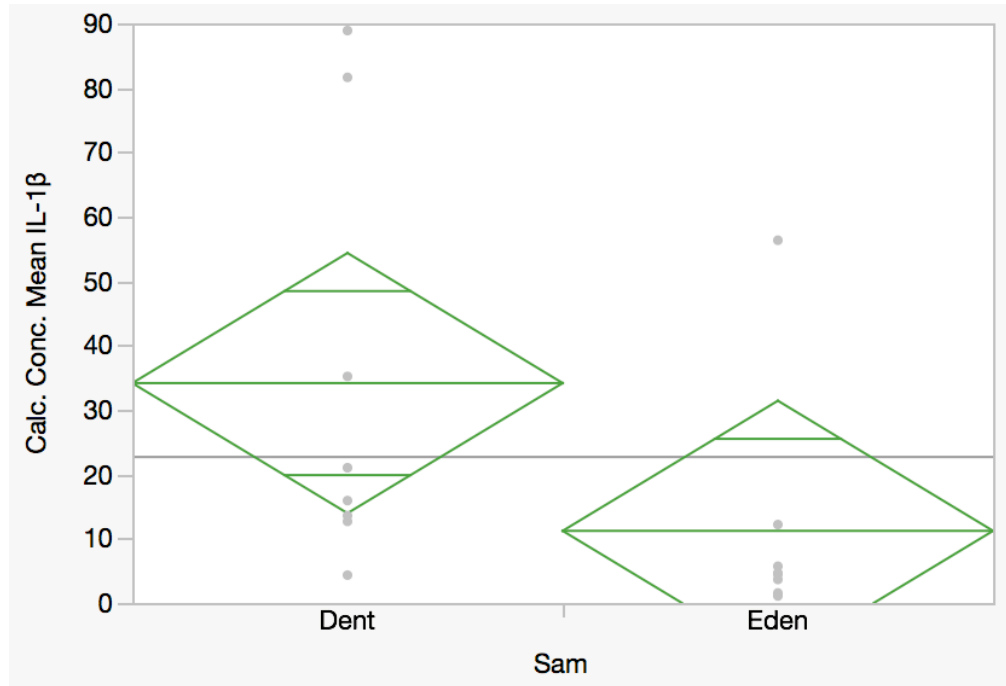

Figure 9a. IL-2 Calculated Concentration Mean Plot (MSD Discovery Workbench 4.0)

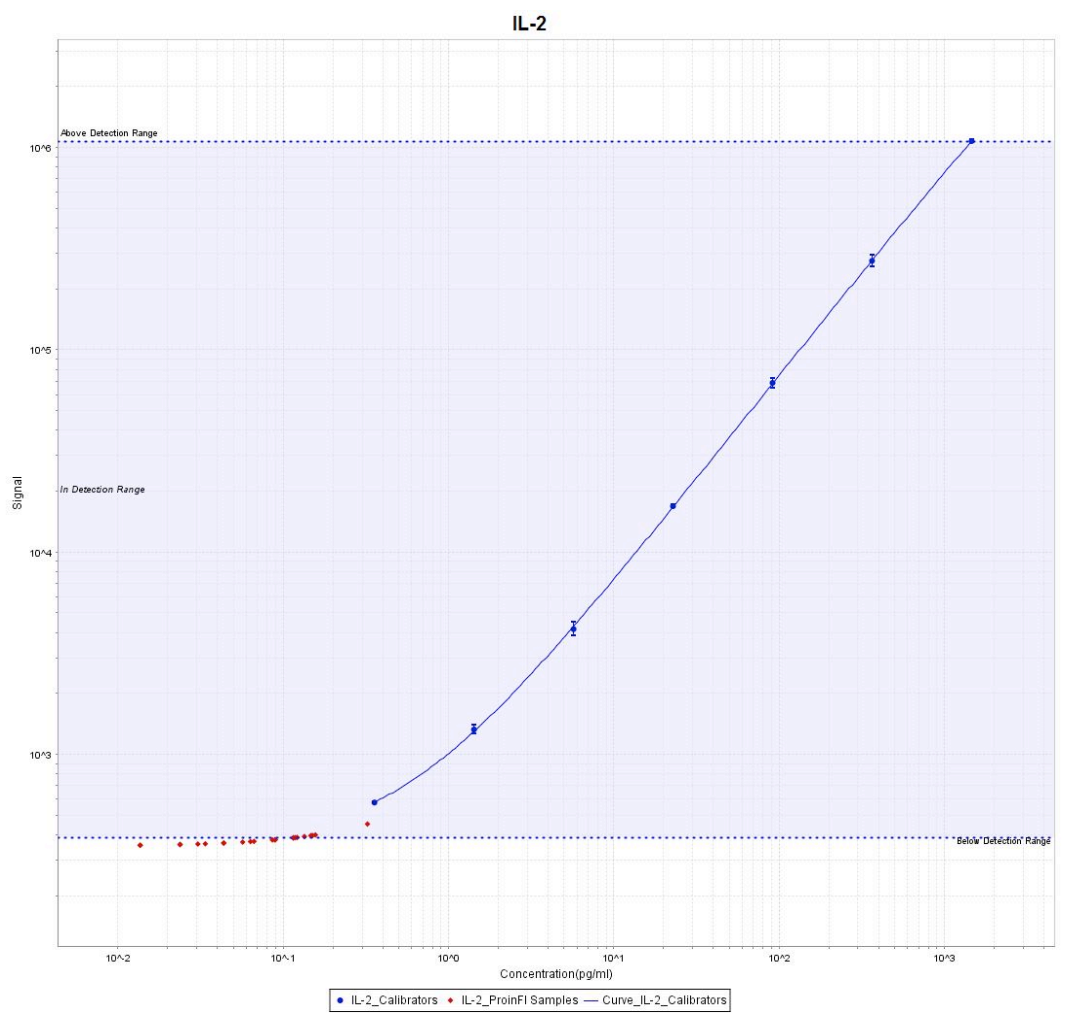

Figure 9b. Statistical Plot for Calculated Concentration Mean of IL-2 


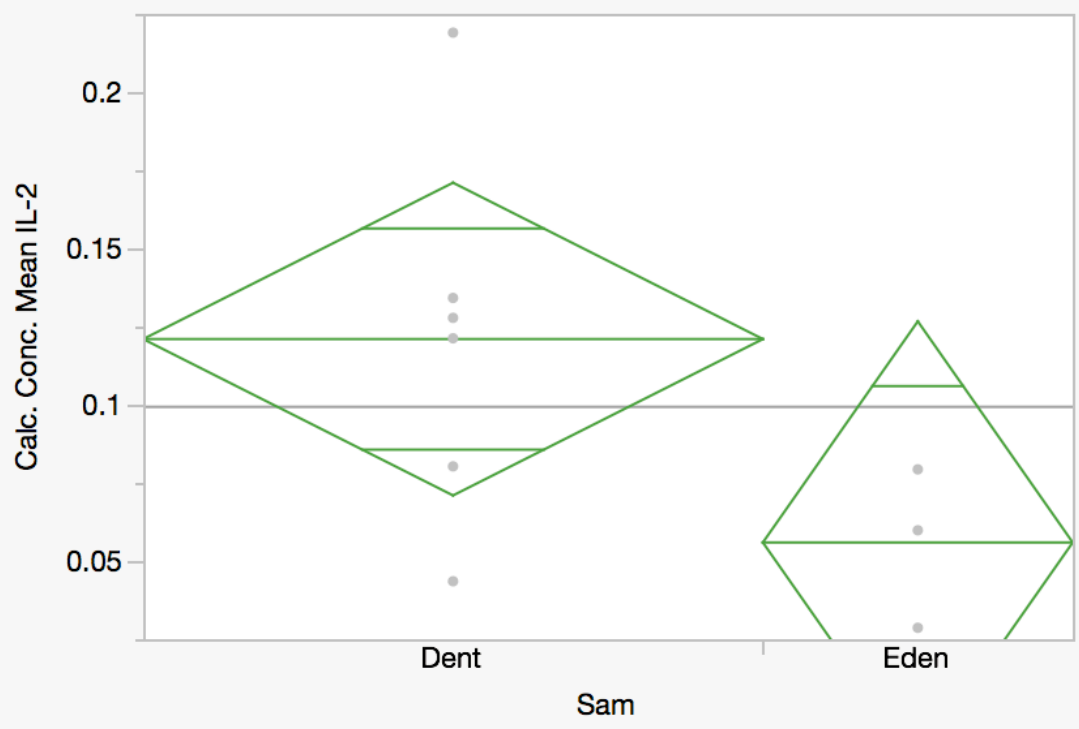

Figure 10a. IL-4 Calculated Concentration Mean Plot (MSD Discovery Workbench 4.0)

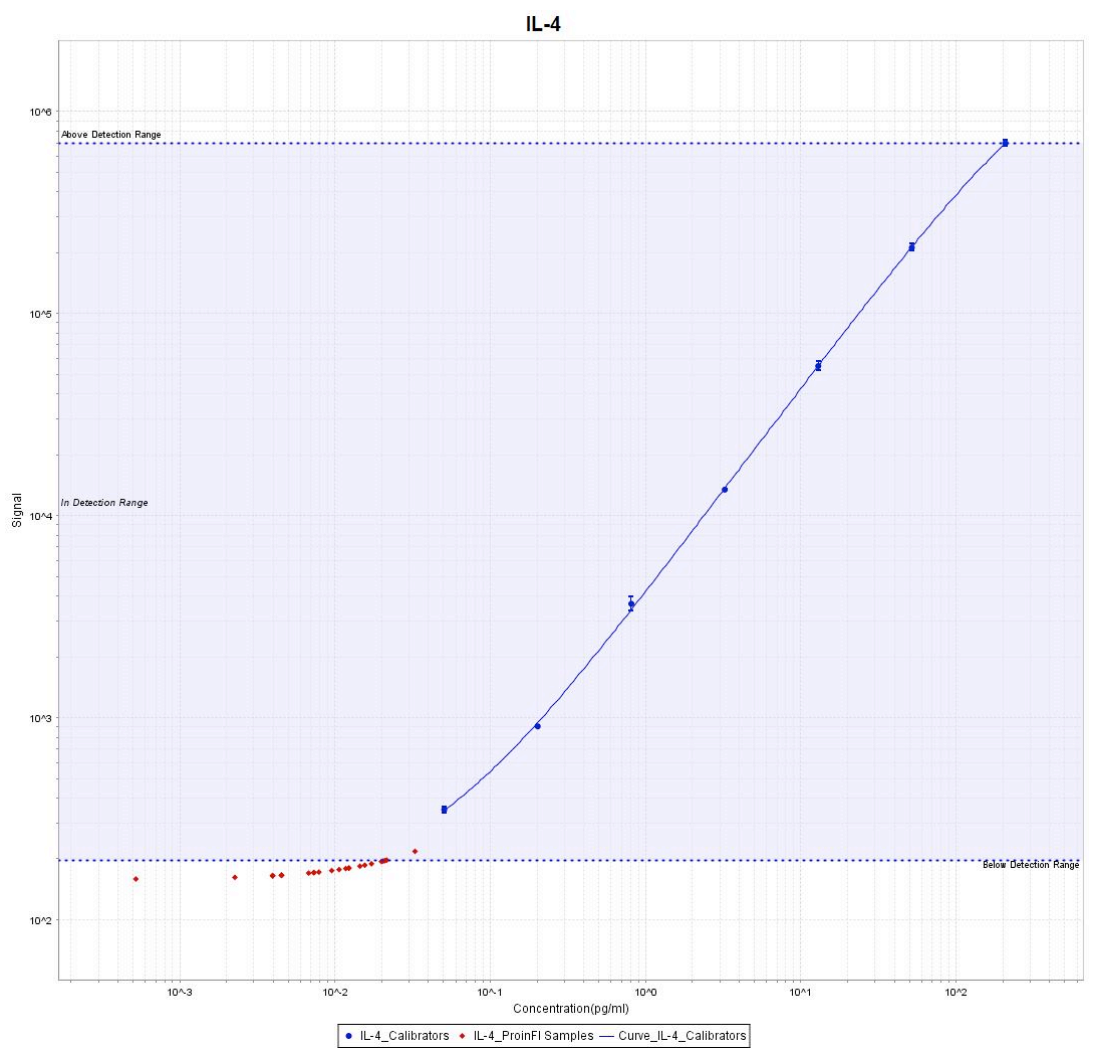

Figure 10b. Statistical Plot for Calculated Concentration Mean of IL-4 


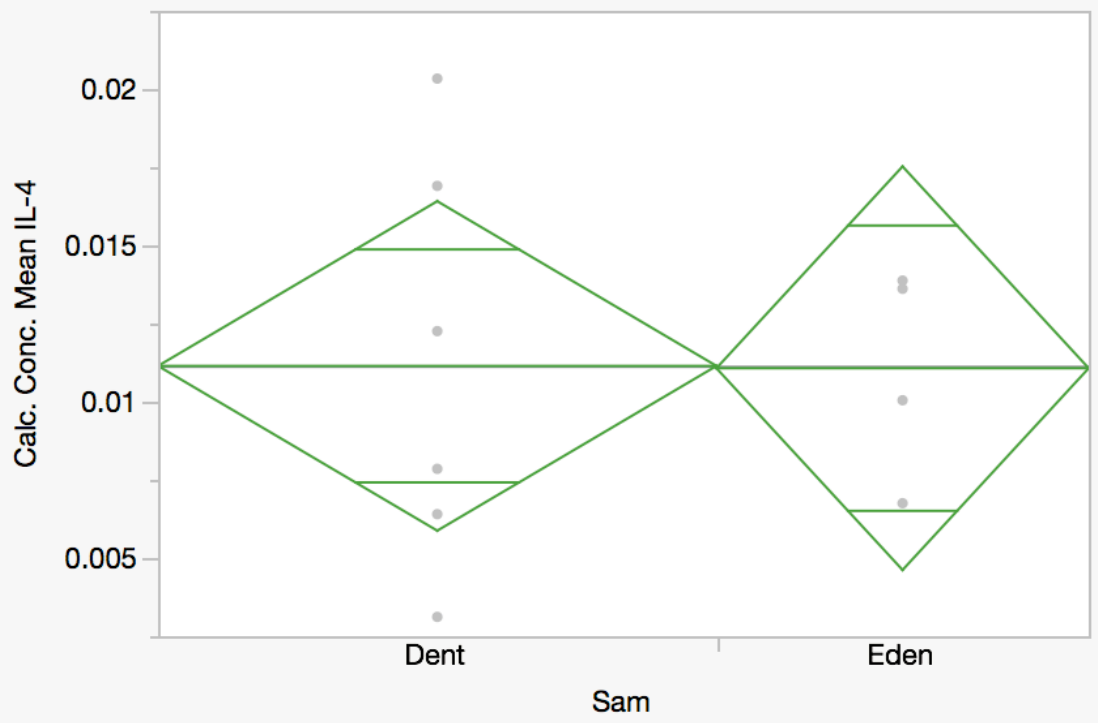

Figure 11a. IL-5 Calculated Concentration Mean Plot (MSD Discovery Workbench 4.0)

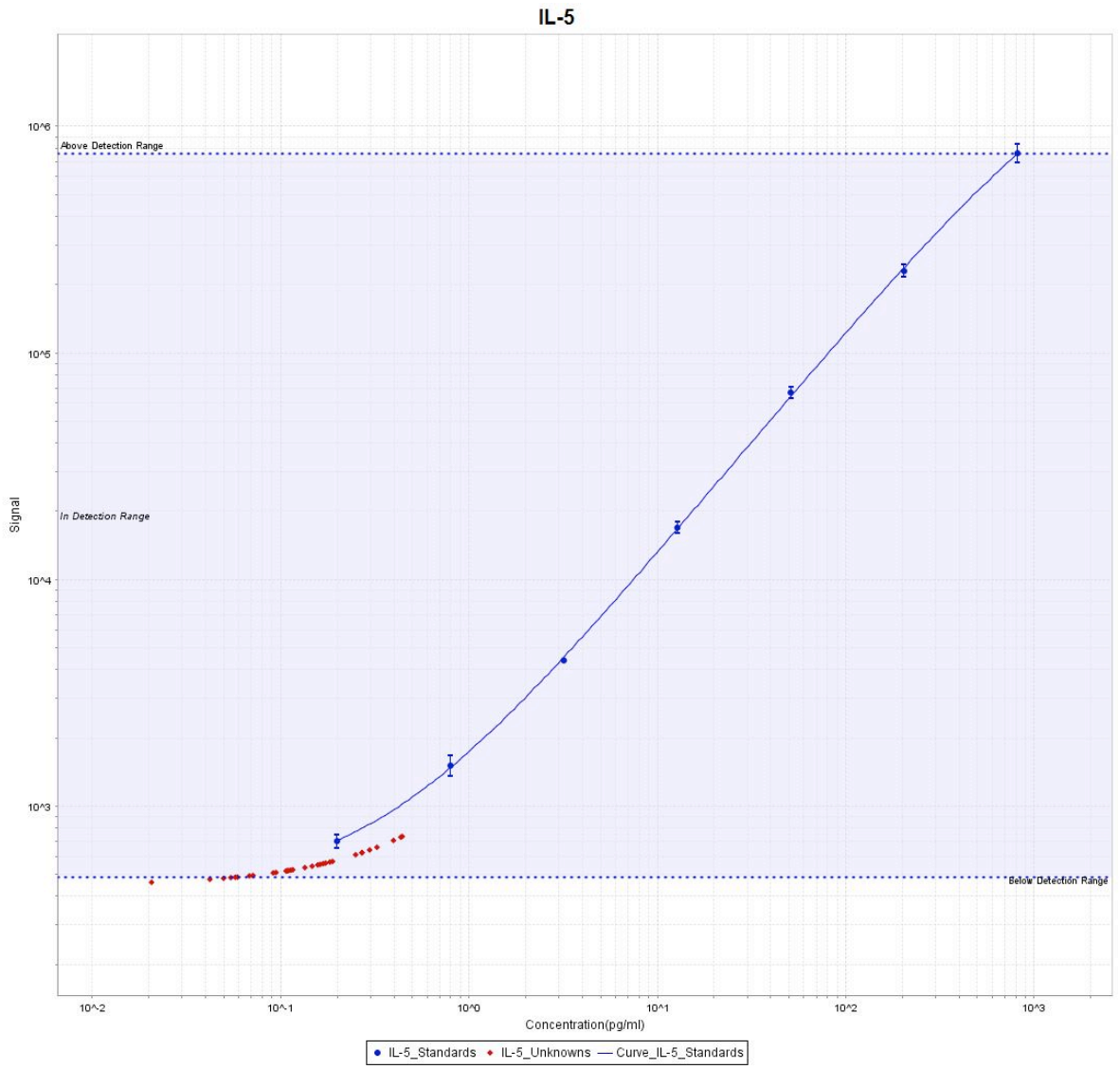

Figure 11b. Statistical Plot for Calculated Concentration Mean of IL-5 


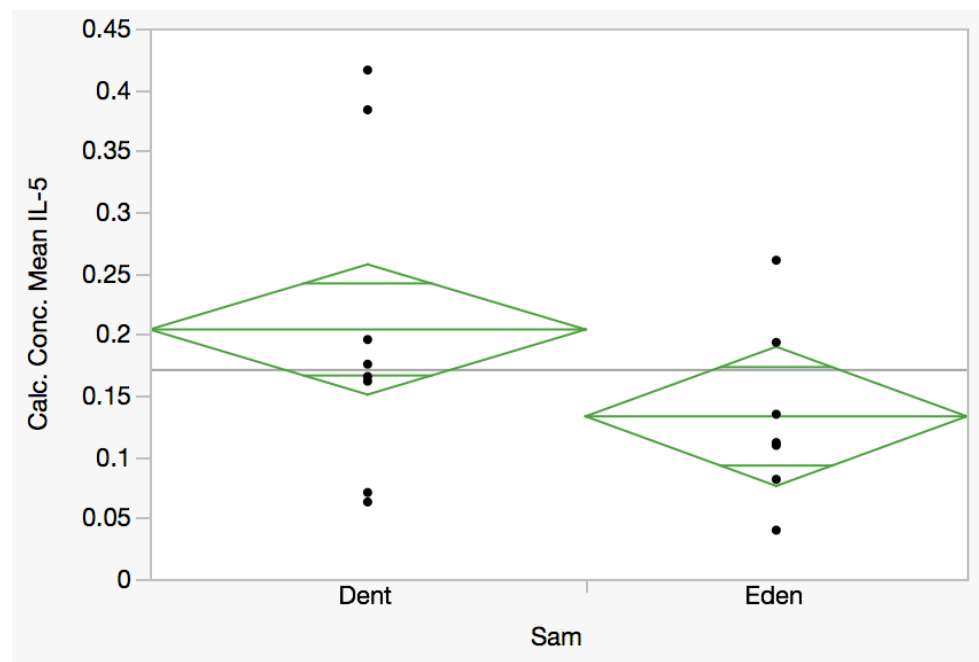

Figure 12a. IL-6 Calculated Concentration Mean Plot (MSD Discovery Workbench 4.0)

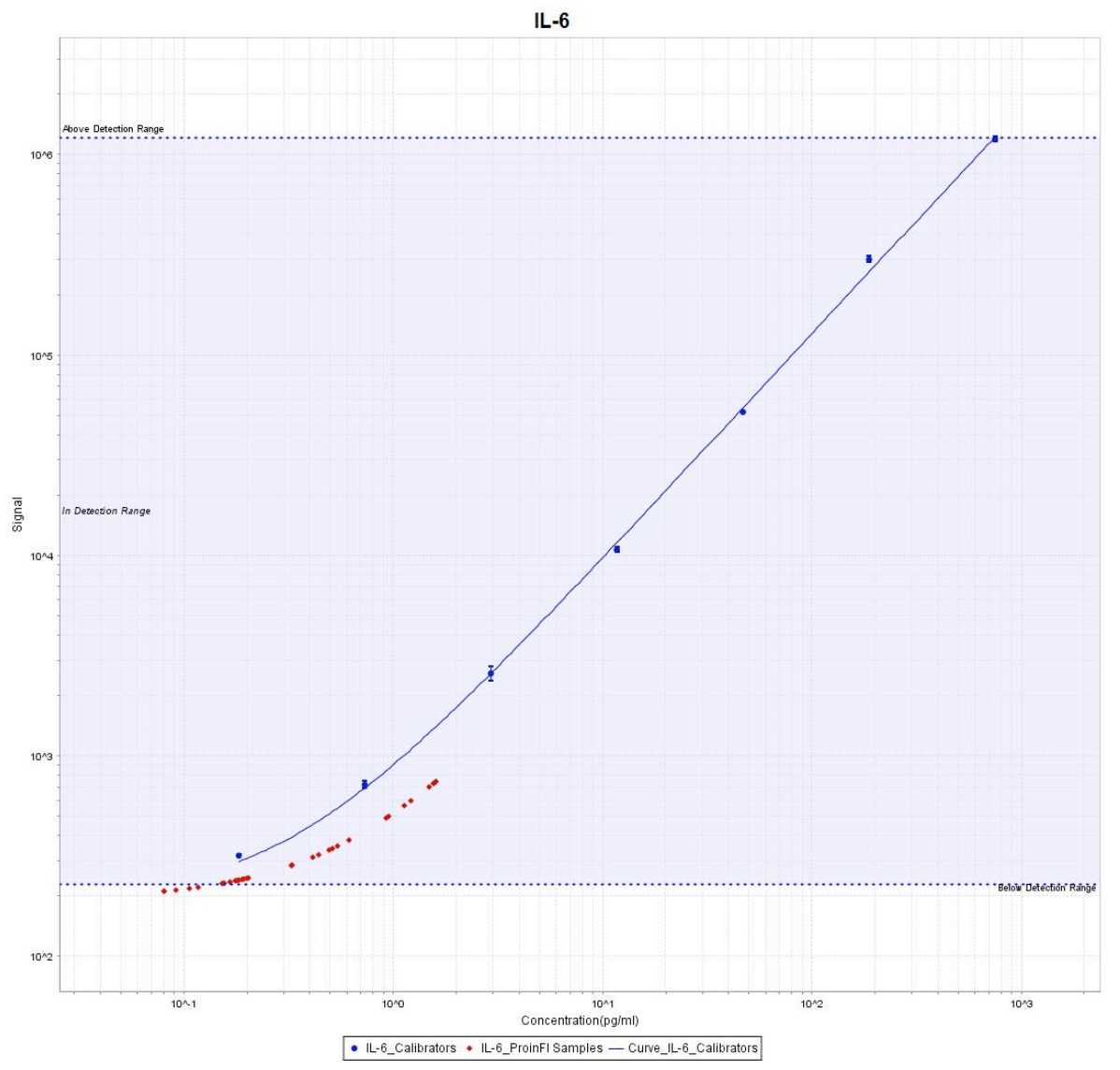

Figure 12 $\beta$. Statistical Plot for Calculated Concentration Mean of IL-6 


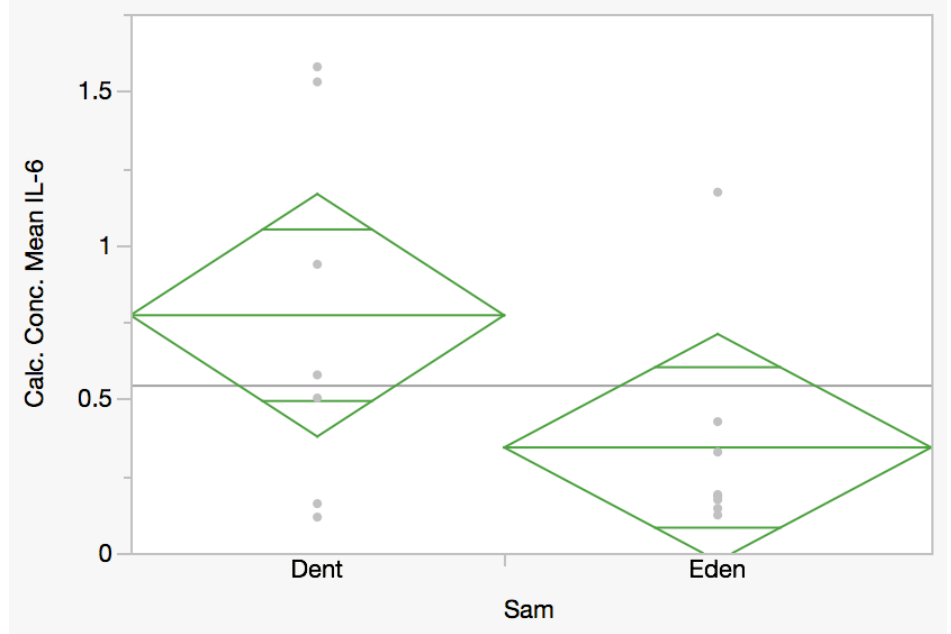

Figure 13a. IL-7 Calculated Concentration Mean Plot (MSD Discovery Workbench 4.0)

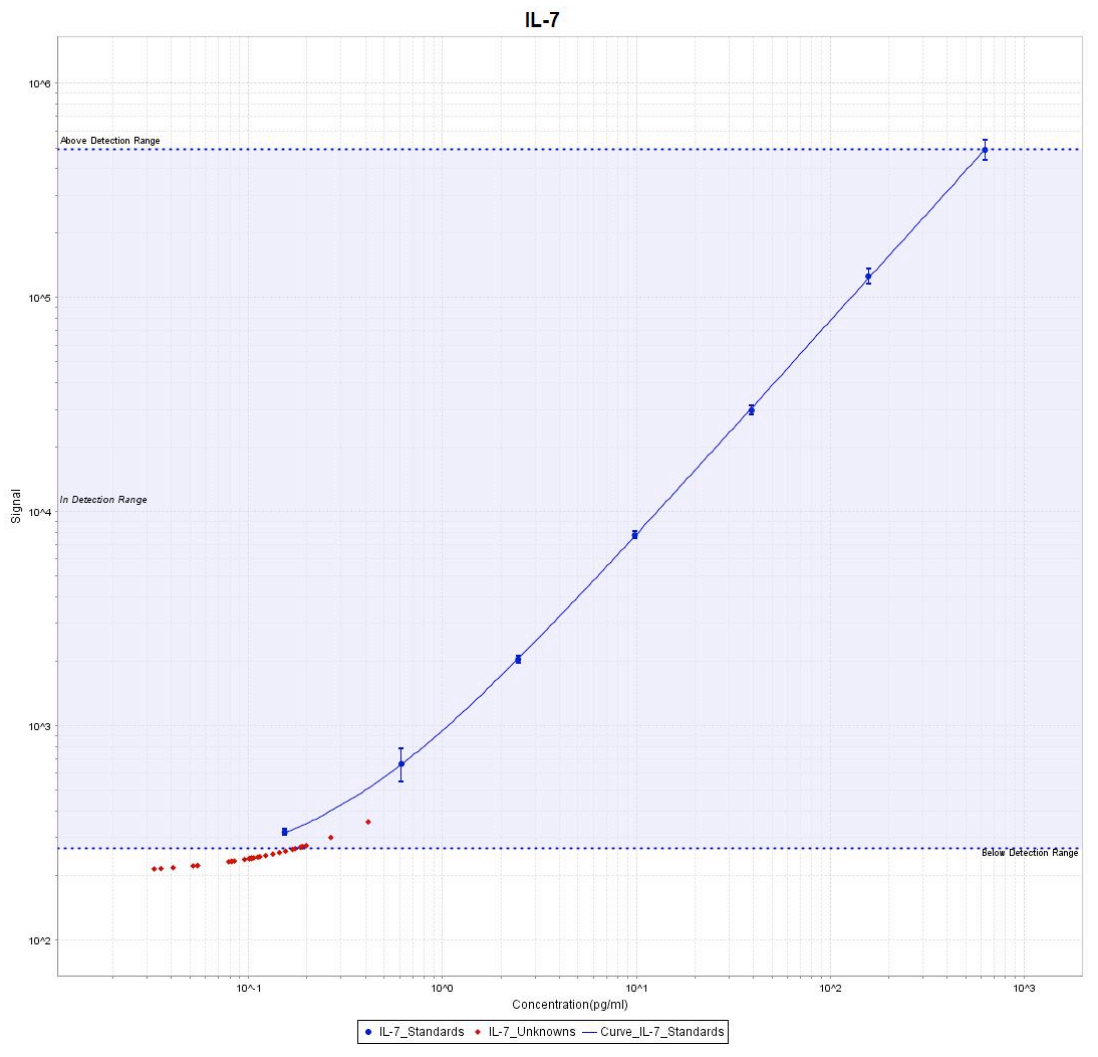

Figure 13b. Statistical Plot for Calculated Concentration Mean of IL-7 


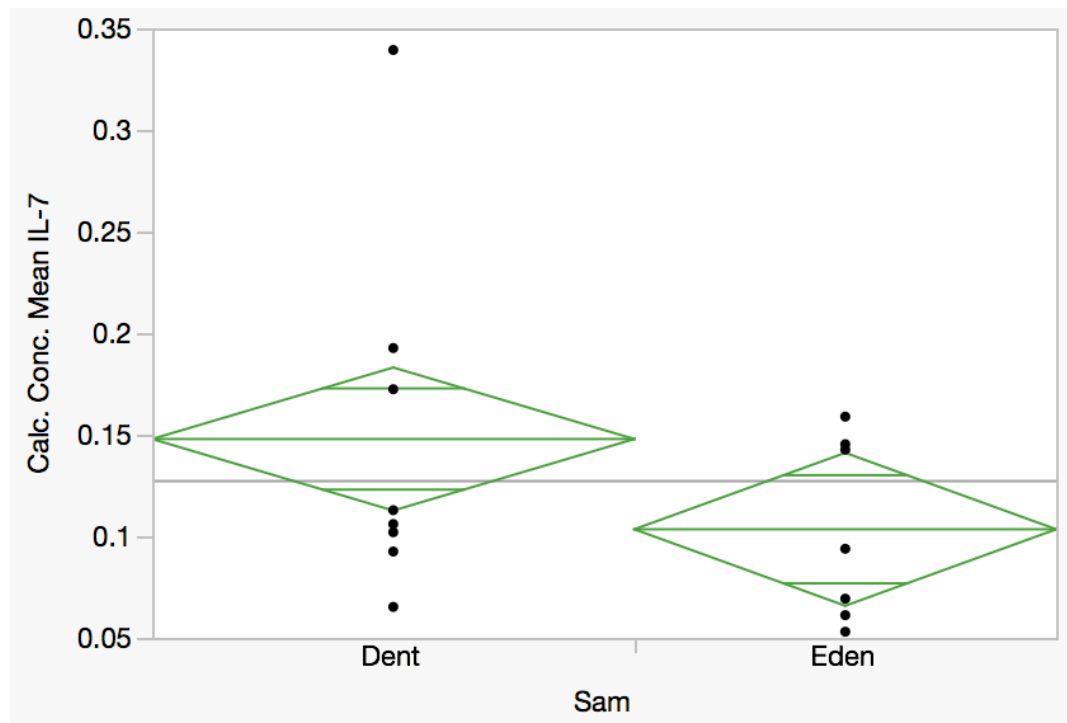

Figure 14a. IL-12p70 Calculated Concentration Mean Plot (MSD Discovery Workbench 4.0)

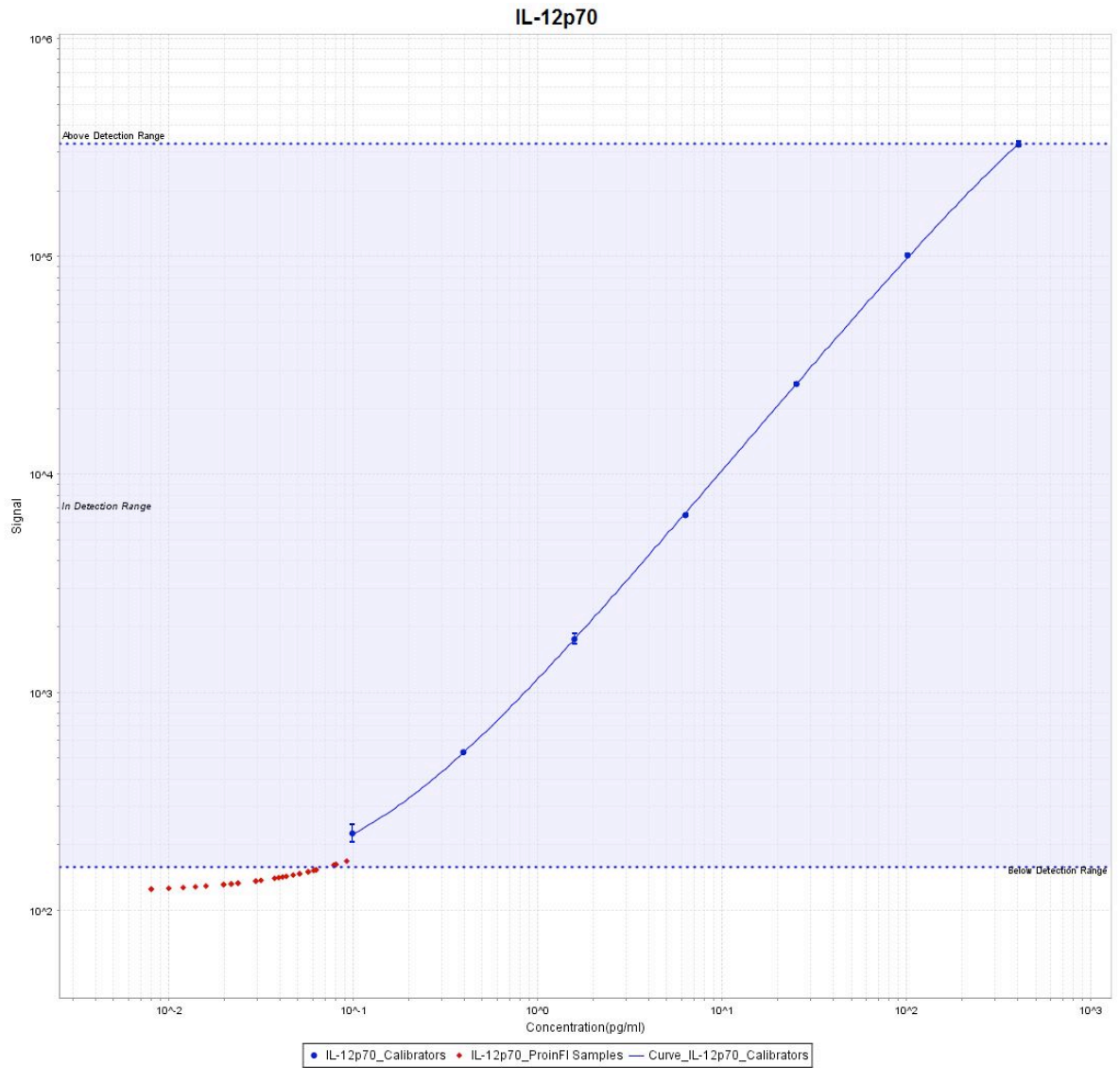

Figure 14b. Statistical Plot for Calculated Concentration Mean of IL-12p70 


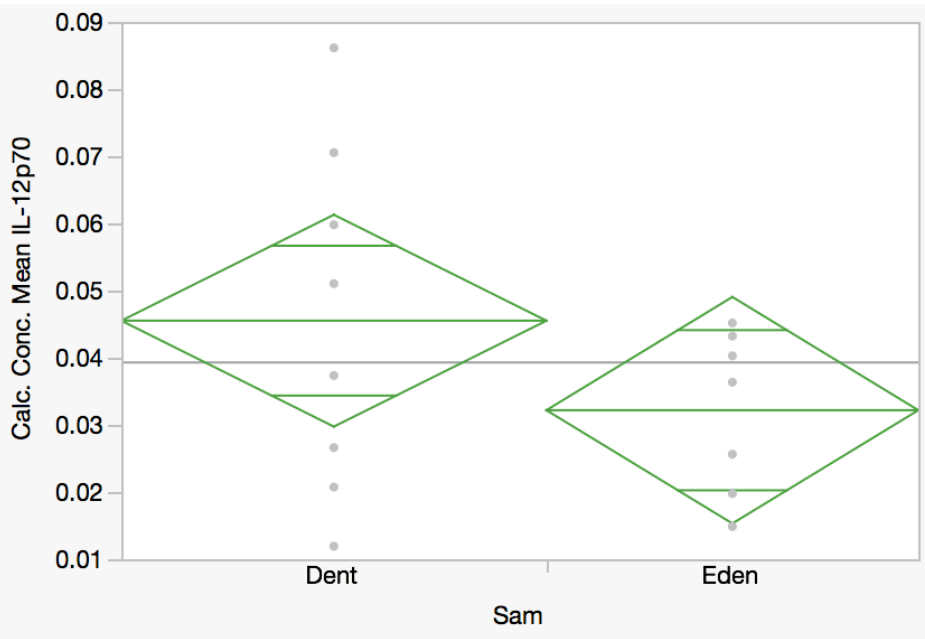

Figure 15a. IL-13 Calculated Concentration Mean Plot (MSD Discovery Workbench 4.0)

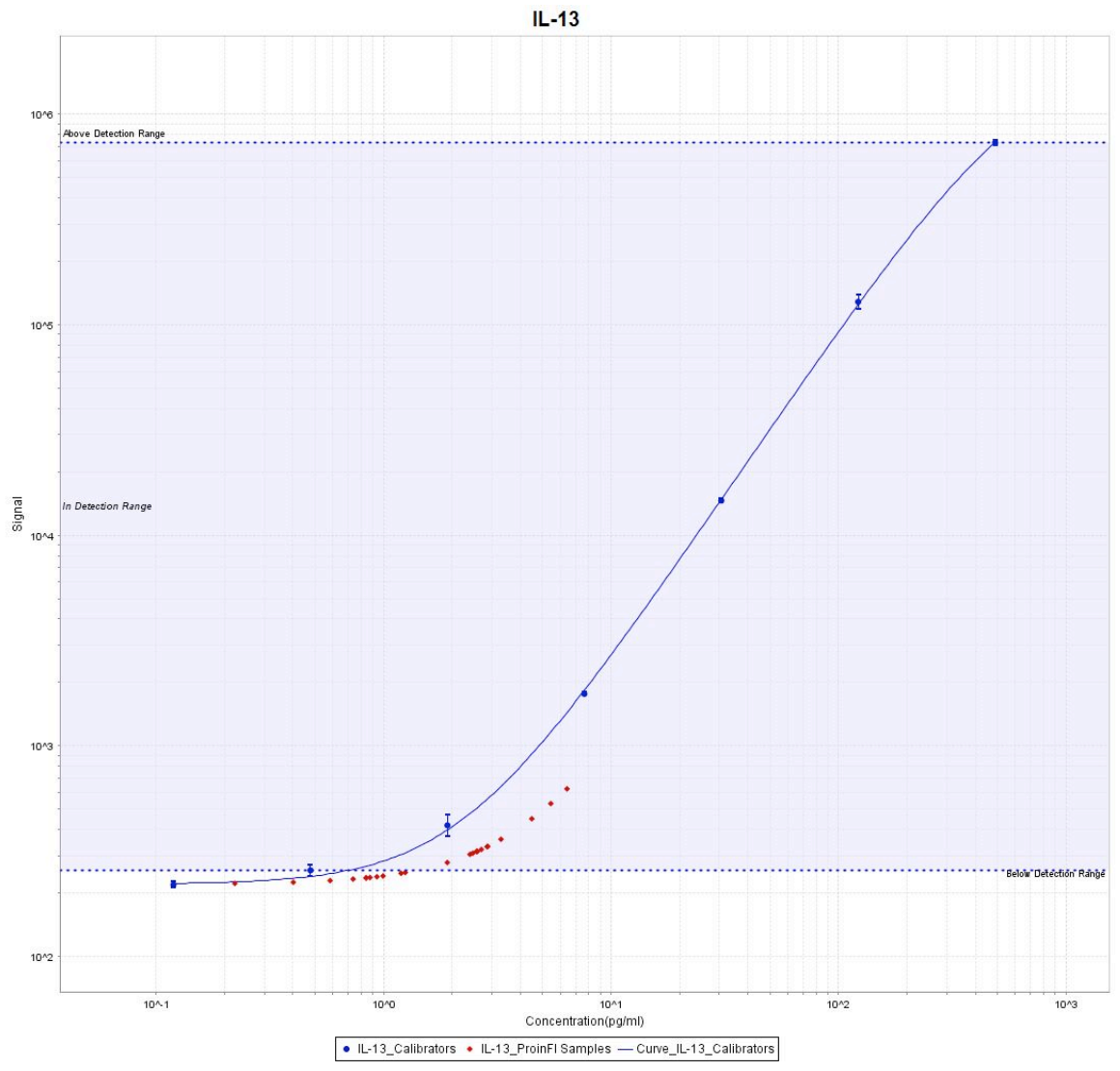

Figure 15b. Statistical Plot for Calculated Concentration Mean of IL-13 


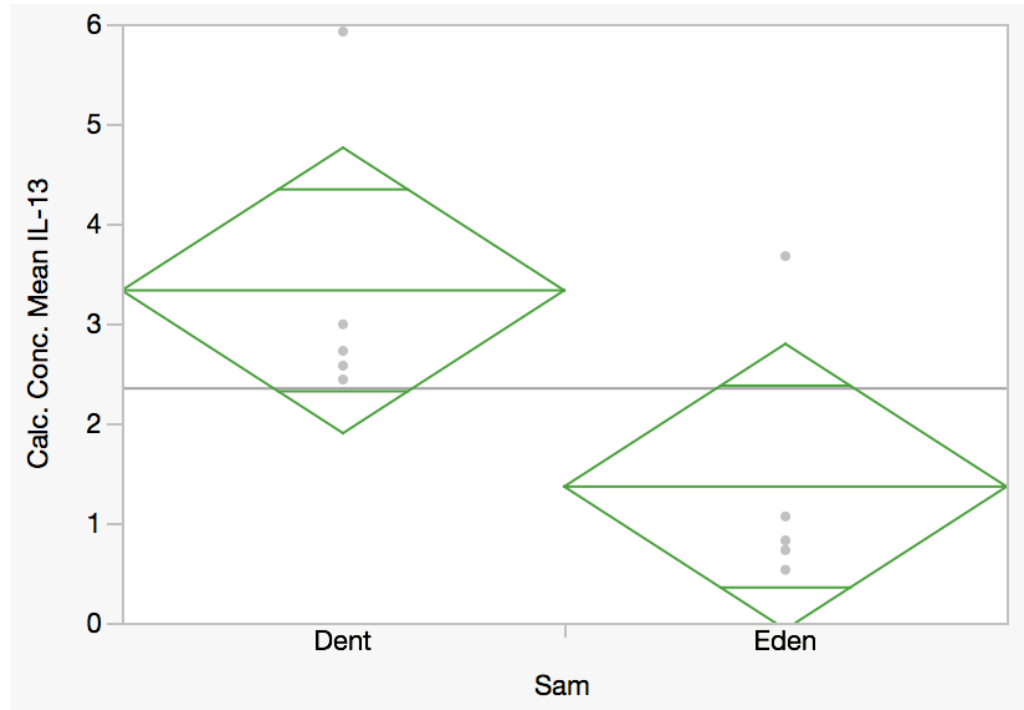

Figure 16a. IL-16 Calculated Concentration Mean Plot (MSD Discovery Workbench 4.0)

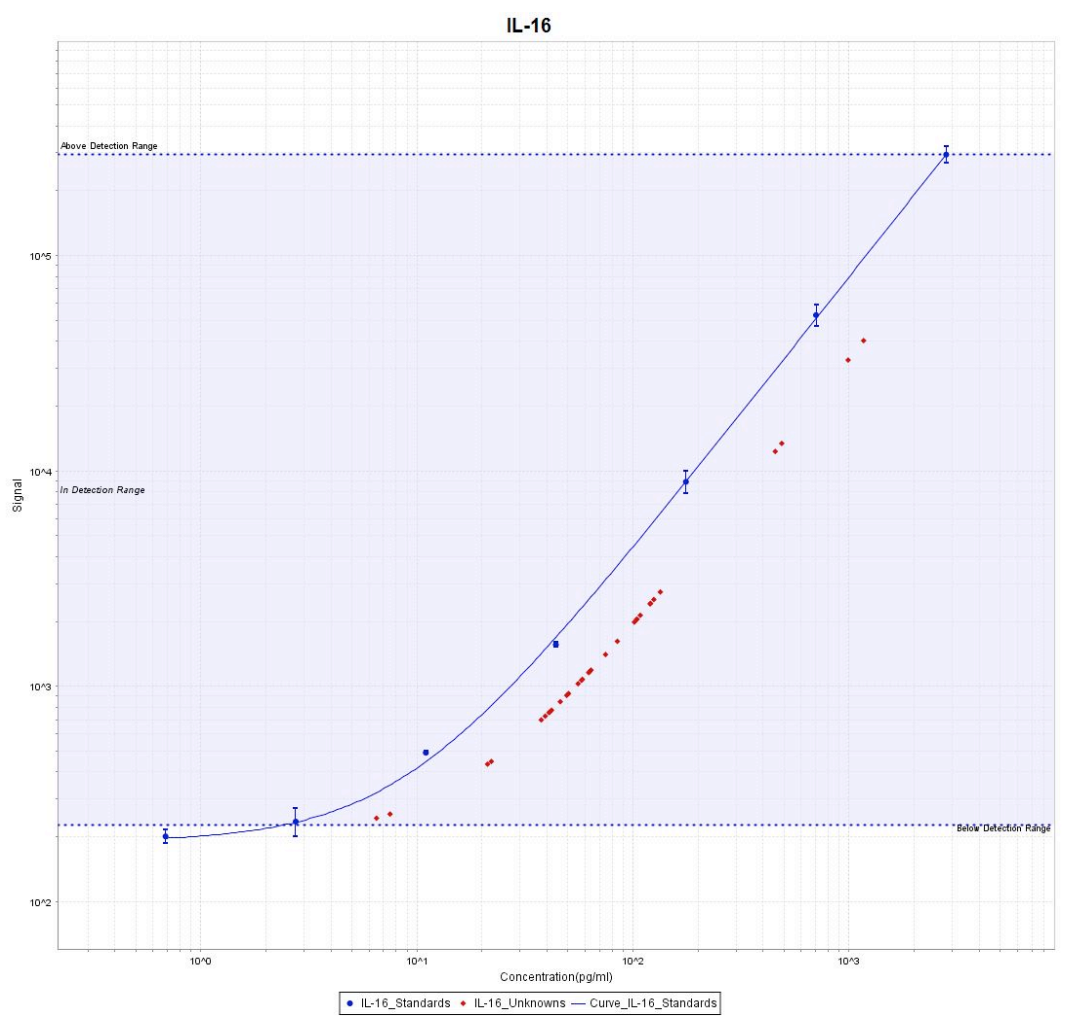

Figure 16b. Statistical Plot for Calculated Concentration Mean of IL-16 


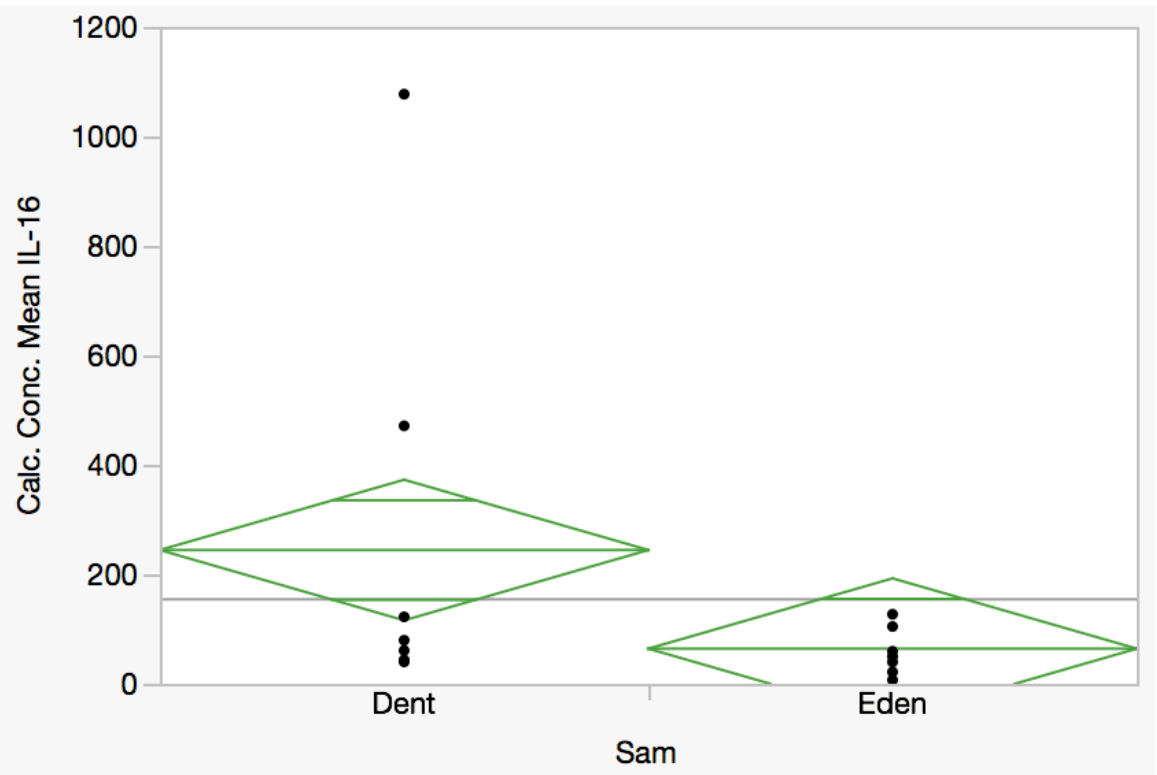

Figure 17a. IL-17a Calculated Concentration Mean Plot (MSD Discovery Workbench 4.0)

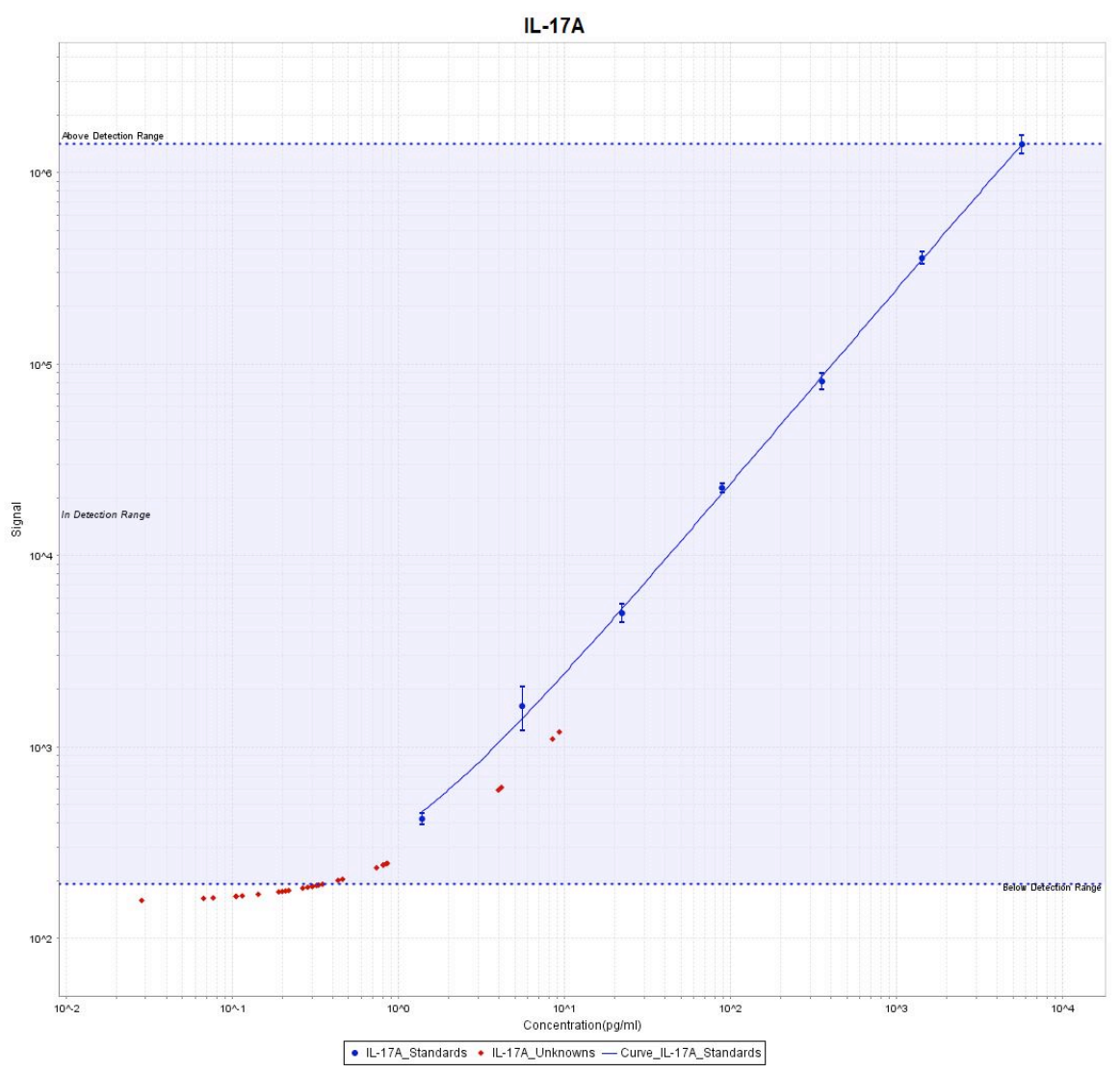

Figure 17b. Statistical Plot for Calculated Concentration Mean of IL-17a 


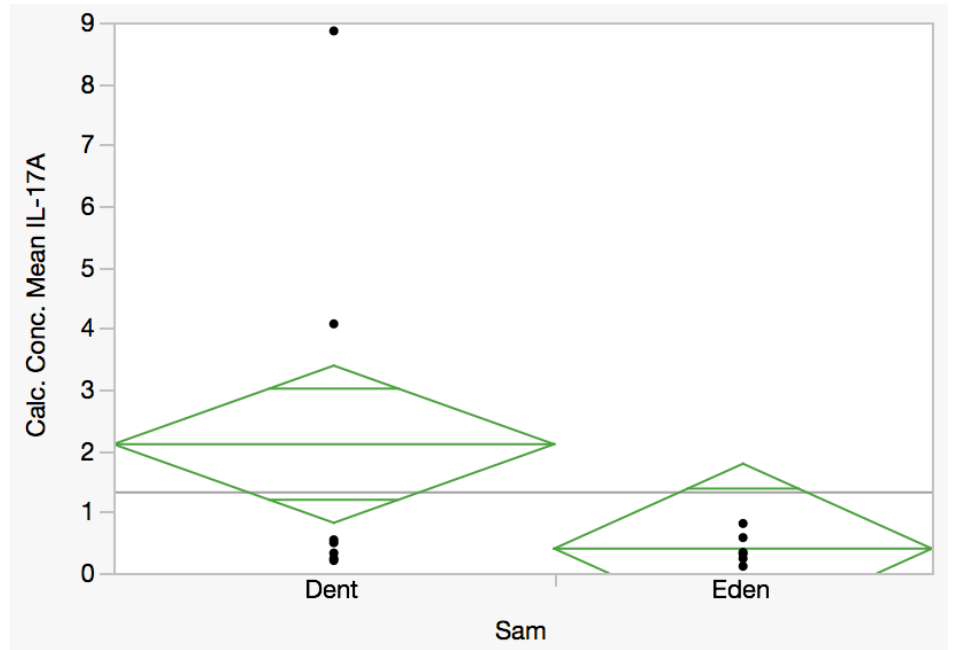

Figure 18a. TNF- $\alpha$ Calculated Concentration Mean Plot (MSD Discovery Workbench 4.0)

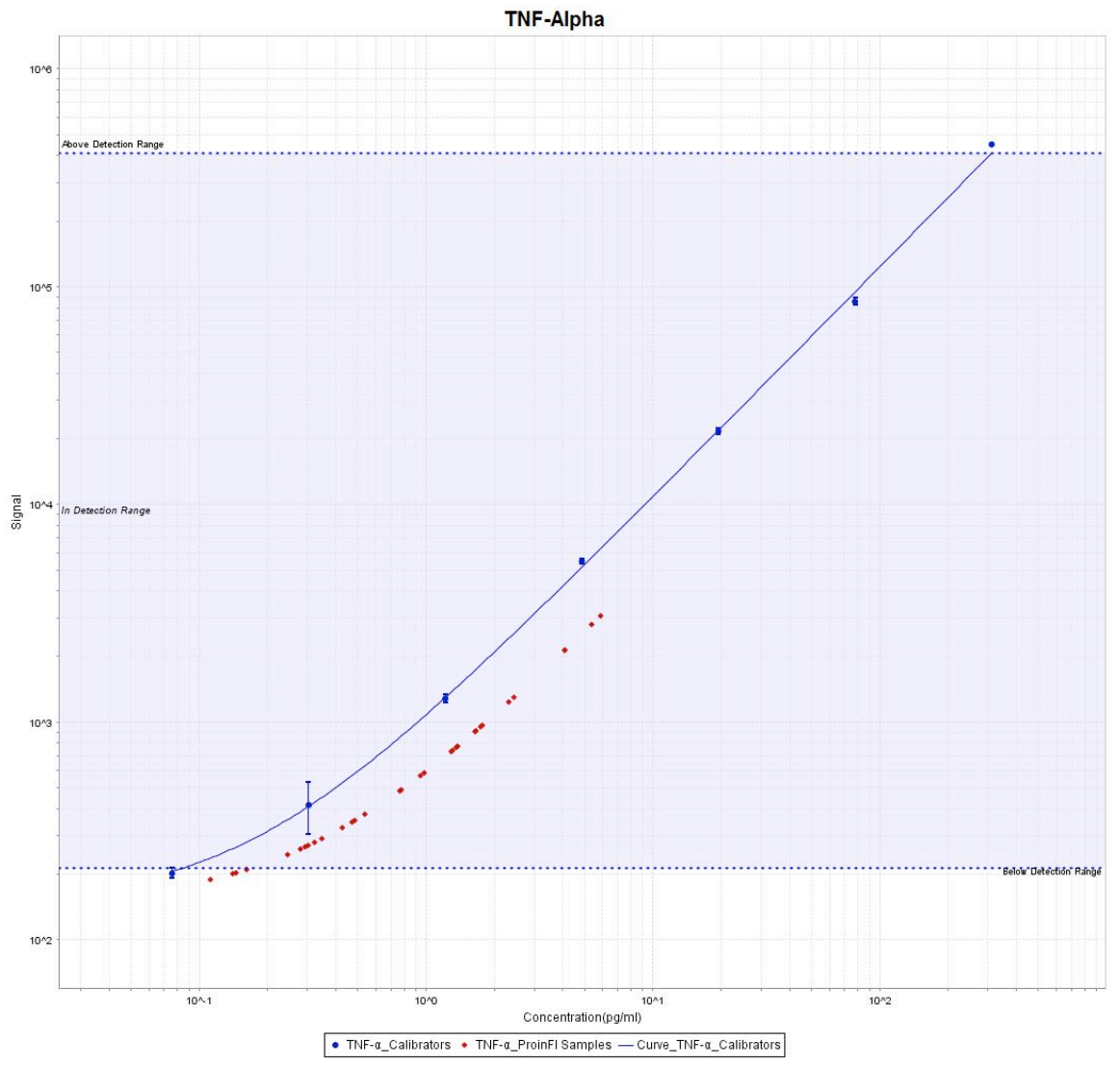

Figure 18b. Statistical Plot for Calculated Concentration Mean of TNFa 


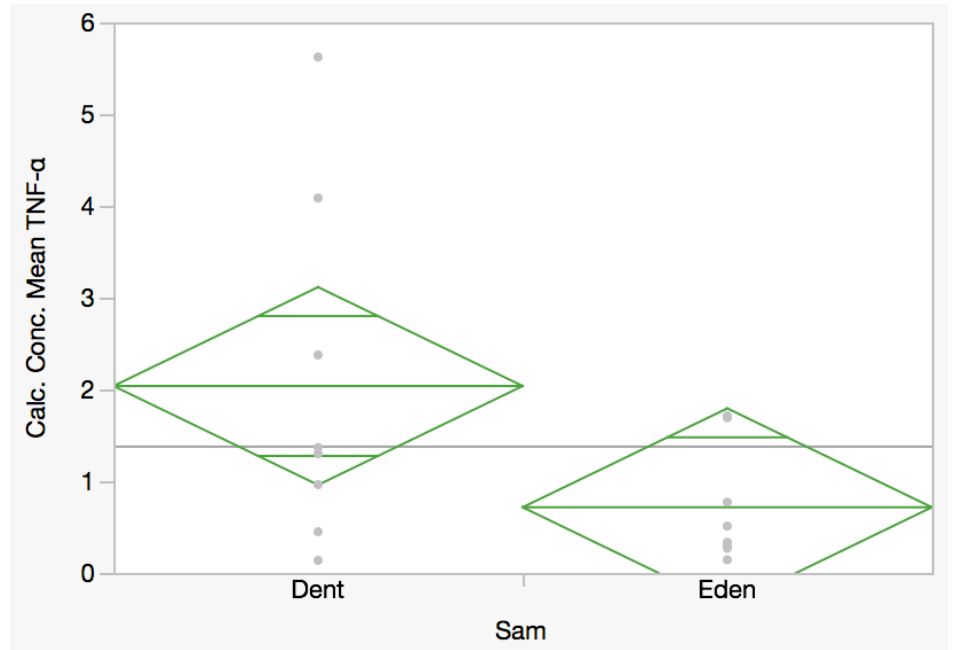

Figure 19a. TNF- $\beta$ Calculated Concentration Mean Plot (MSD Discovery Workbench 4.0)

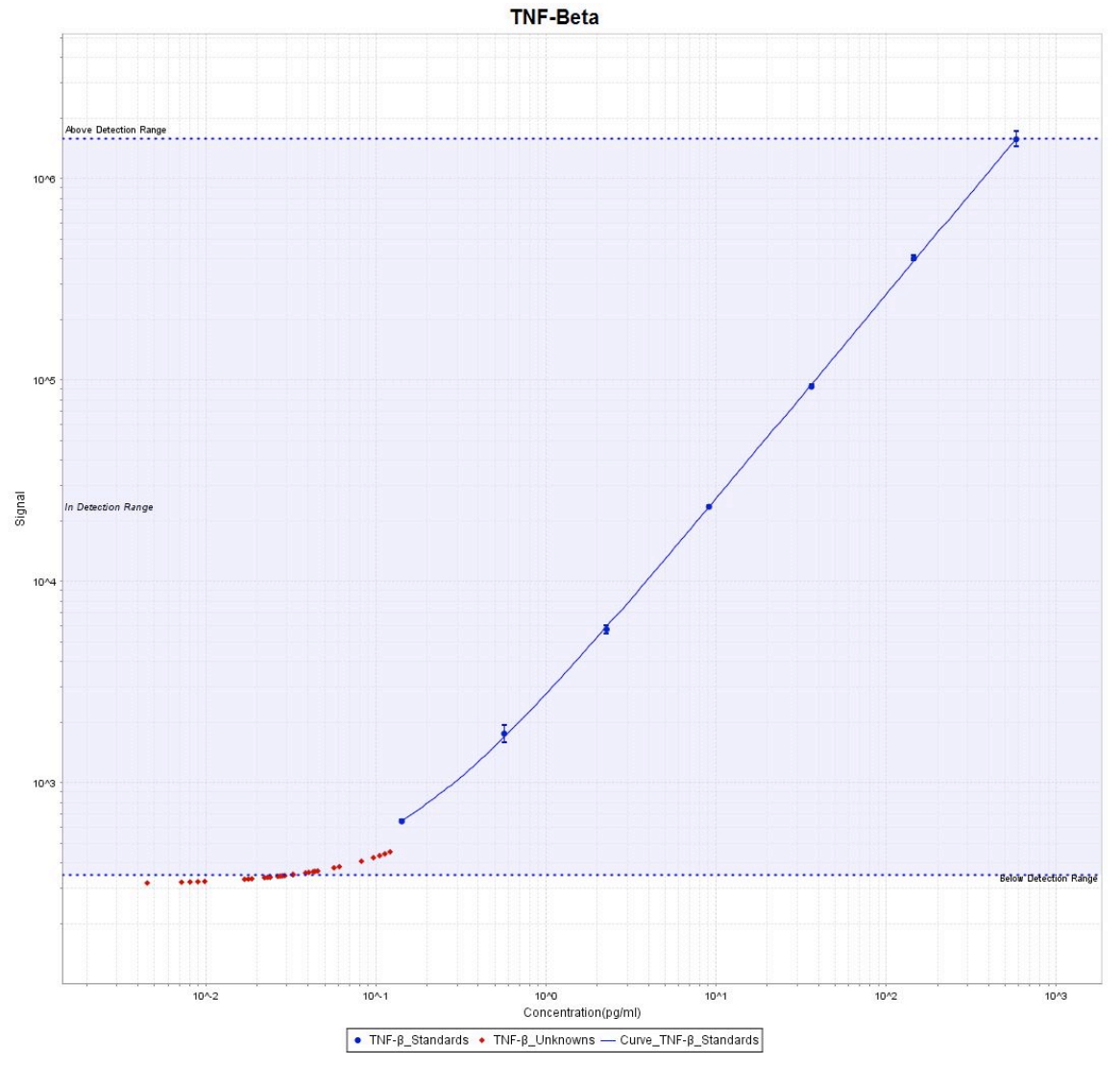

Figure 19b. Statistical Plot for Calculated Concentration Mean of TNF- $\beta$ 


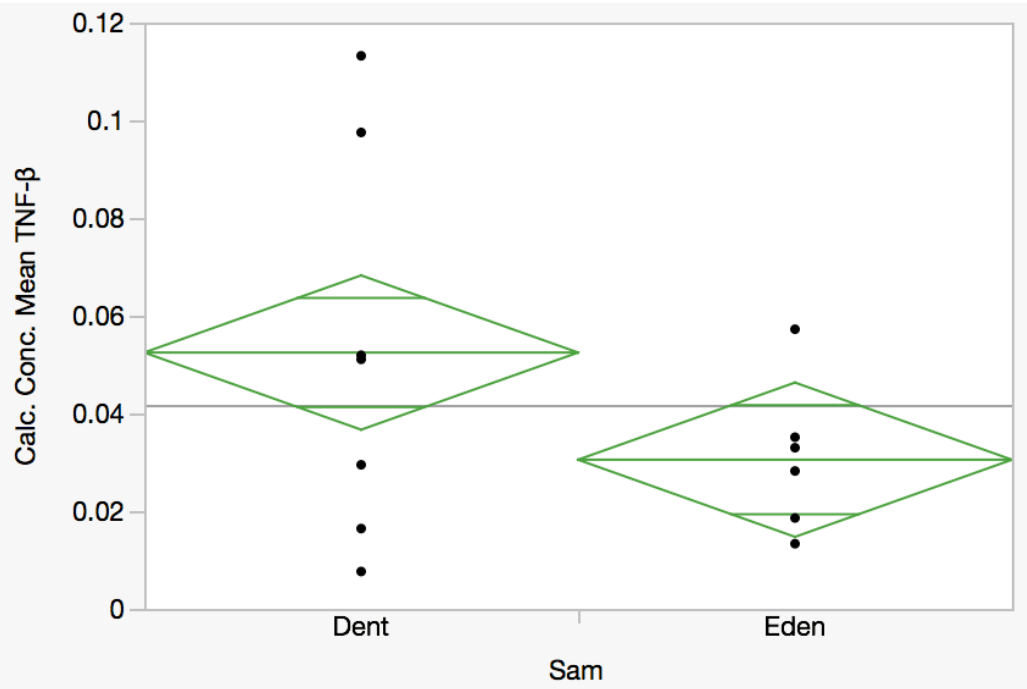

Figure 20a. IL-8 Calculated Concentration Mean Plot (MSD Discovery Workbench 4.0)

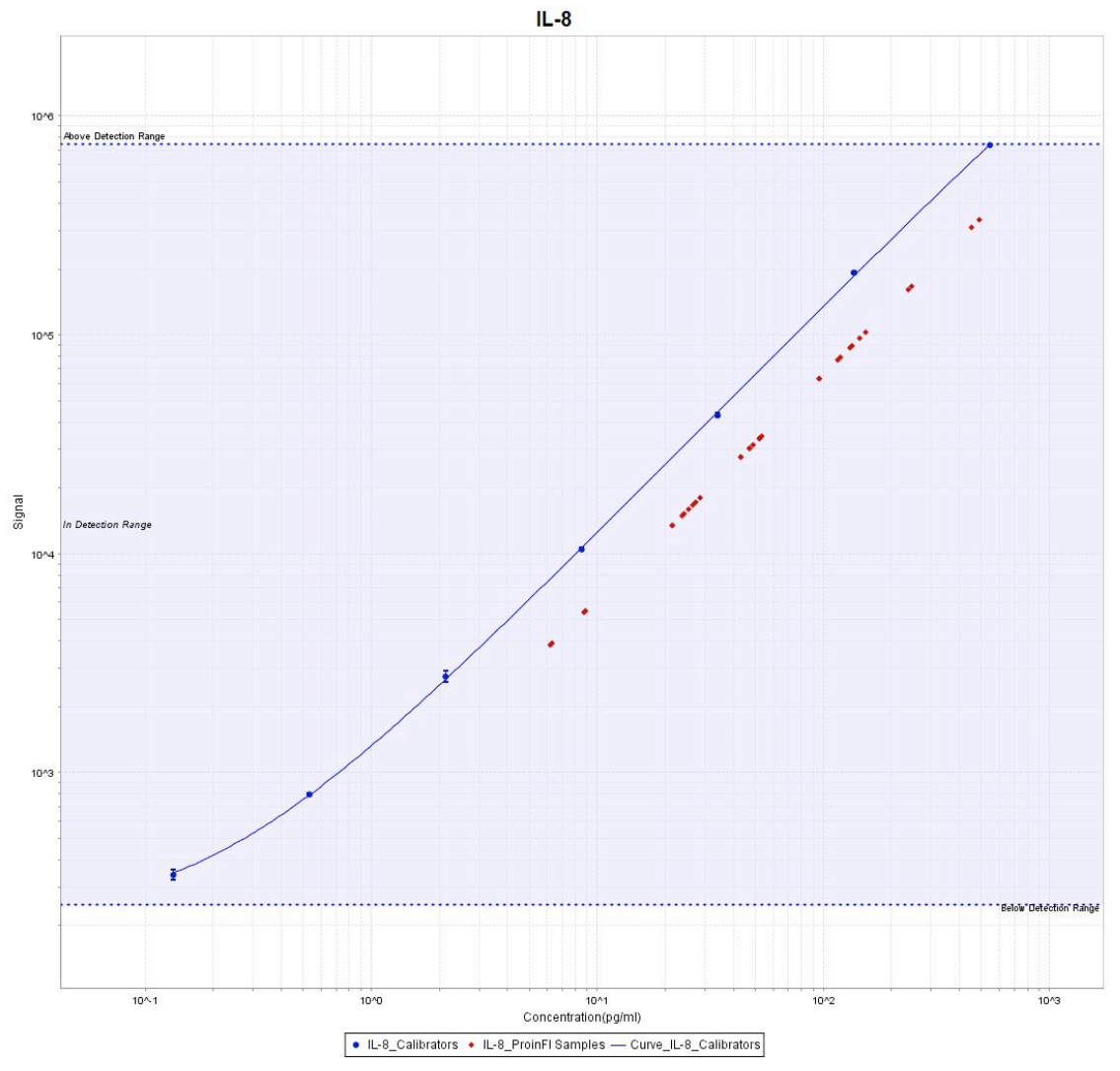

Figure 20b. Statistical Plot for Calculated Concentration Mean of IL-8 


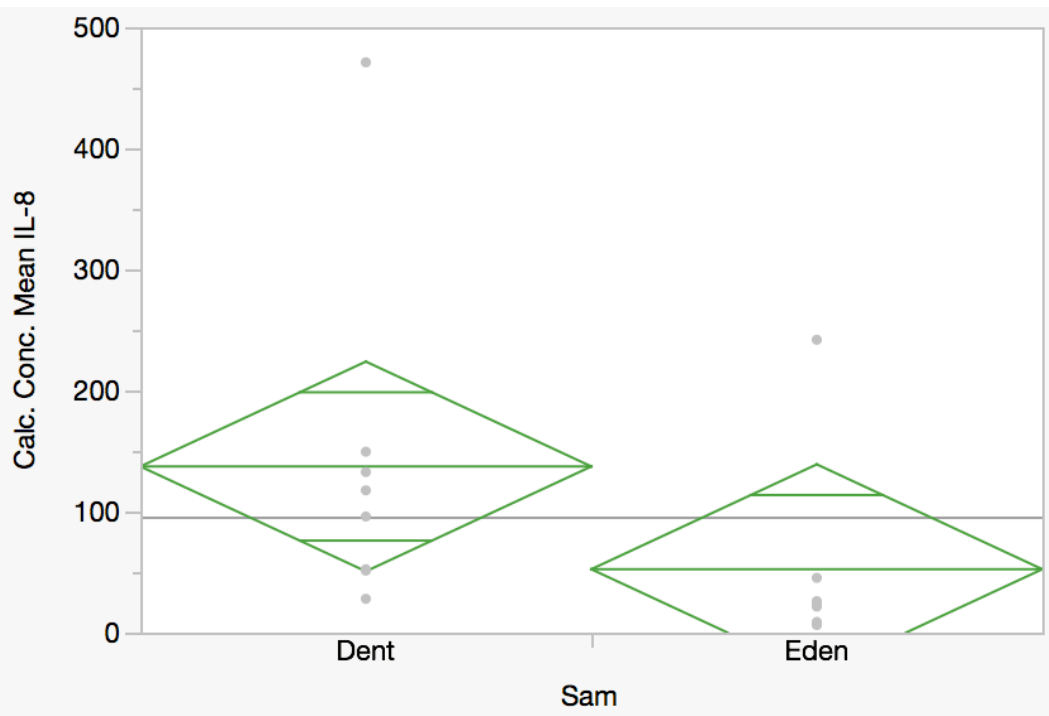

